\title{
Copyright
}

by

Jill Elaine Rader

2003 
The Dissertation Committee for Jill Elaine Rader certifies that this is the approved version of the following dissertation:

\section{The Egalitarian Relationship in Feminist Therapy}

Committee:

Lucia A. Gilbert, Supervisor

Ann Brooks

Frank Richardson

Stephanie Rude

Diane Schallert 


\title{
The Egalitarian Relationship in Feminist Therapy
}

\author{
by
}

Jill Elaine Rader, B.A., M.I.J.

\author{
Dissertation \\ Presented to the Faculty of the Graduate School of \\ the University of Texas at Austin \\ in Partial Fulfillment \\ of the Requirements \\ for the Degree of \\ Doctor of Philosophy
}

The University of Texas at Austin

December 2003 


\title{
The Egalitarian Relationship in Feminist Therapy
}

\author{
Publication No.
}

Jill Elaine Rader, Ph.D.

The University of Texas at Austin, 2003

Supervisor: Lucia A. Gilbert

Feminist therapy has revolutionized counseling practice and offered a model of empowerment for all therapy approaches for the past three decades. However, the long-assumed claim that feminist therapists are more likely to engage in power-sharing behaviors with their clients has never been subjected to quantitative research. The current investigation, conducted with 42 therapists and their clients, was an attempt to address this gap in the research. Female practicing therapists and one of their female clients were asked to complete self-report measures. Therapists completed measures assessing their identity as a feminist therapist (yes/no), their feminist perspective (Feminist Perspectives Scale), their use of feminist therapy behaviors (Feminist Therapy Behavior Checklist), and their use of power-sharing behaviors (Therapy with Women Scale). In addition, therapists were asked to explain, in narrative format, why they either identified as a feminist therapist or did not identify as a feminist therapist. Clients completed measures assessing their perceptions of both treatment collaboration (Working Alliance Inventory - Client Form) and their therapists' power-sharing behaviors (Client Therapy with Women Scale). As hypothesized, therapists who identified themselves as feminist therapists were more likely to report engaging in power-sharing behaviors when compared to therapists who did not identify themselves as feminist therapists. Furthermore, as hypothesized, clients of feminist 
therapists were more likely to report that their therapists engaged in power-sharing behaviors when compared to clients of therapists who did not identify as feminist therapists. An analysis of the open-ended responses as to why therapists identified as a feminist therapist or did not identify as a feminist therapist supported quantitative findings. Responses indicated that those who identified as feminist therapists were more likely to describe an attention to power and to sociocultural context in their therapeutic work. These findings demonstrating the link between identification as a feminist therapist and perceptions of power-sharing are the first of their kind in the literature, and may help to clarify what distinguishes feminist therapy from other therapy approaches. Implications for feminist therapy practice, as well as for counseling practice, are discussed. 


\section{Table of Contents}

List of Tables $\quad$ viii

Review of the Literature $\quad 1$

Origins of Feminist Therapy 2

Feminist Critiques of Traditional Psychotherapy 4

Feminist Contributions to Psychological Theory and Practice 6

$\begin{array}{ll}\text { Feminist Therapy Defined } & 10\end{array}$

$\begin{array}{ll}\text { A Heterogenous Definition } & 10\end{array}$

$\begin{array}{ll}\text { Core Tenets } & 11\end{array}$

The Egalitarian Relationship $\quad 13$

Research on Feminist Therapy Process $\quad 16$

Goals of this Dissertation Study 20

$\begin{array}{ll}\text { Methodology } & 23\end{array}$

Procedures 23

$\begin{array}{ll}\text { Participants } & 25\end{array}$

$\begin{array}{ll}\text { Measures } & 29\end{array}$

$\begin{array}{ll}\text { Therapist Measures } & 29\end{array}$

Therapist's Feminist Identity 29

Therapist's Feminist Perspective (FPS) 29

Feminist Therapy Behaviors (FTBC) 30

Power-Sharing Behaviors (TWS) $\quad 32$

Client Measures

Power-Sharing Behaviors (CTWS) 33

Treatment Collaboration (WAI-C) 33

$\begin{array}{ll}\text { Hypotheses } & 36\end{array}$

Results

Tests of the Main Hypotheses for Therapists and Clients 37

Intercorrelations Among the Measures $\quad 40$

Analyses of Therapist Responses to the Open-Ended Question 42

$\begin{array}{ll}\text { Discussion } & 46\end{array}$

Appendices $\quad 55$

Appendix A: Participant Recruitment Ad 55

Appendix B: Instructions to Therapists 56

Appendix C: Instructions to Clients $\quad 57$

Appendix D: Participant Consent Form $\quad 58$

Appendix E: Therapist Information Form $\quad 62$

Appendix F: Client Information Form 63 
Appendix G: Therapist Self-Identification as a Feminist Therapist 64

Appendix H: Feminist Perspectives Scale (FPS) 65

Appendix I: $\quad$ Feminist Therapy Behavior Checklist (FTBC) 68

Appendix J: $\quad$ Therapy with Women Scale (TWS) 70

Appendix K: Client Therapy with Women Scale (CTWS) 72

Appendix L: Working Alliance Inventory - Client Form (WAI-C) 74

Appendix M: Instructions to Coders 76

$\begin{array}{ll}\text { Bibiography } & 77\end{array}$

$\begin{array}{ll}\text { Vita } & 85\end{array}$ 


\section{List of Tables}

Table 1: $\quad$ Item Means and Standard Deviations, Therapist and Client Measures for Participants in the Two Categories

Table 2: $\quad$ Results of One-Tailed T Tests Comparing Self-Identified Feminist Therapists and Therapists Not Self-Identified as Feminist Therapists and their Clients

Table 3: Intercorrelations Between Therapist Age, Experience, and Client and Therapist Measures 


\section{Review of the Literature}

Feminist therapy is a relatively new counseling approach that emerged in a 1970s milieu of consciousness-raising groups and Second-Wave Feminism. However, feminist critiques of the mental health establishment have been around for the past 100 years, and it was in that rich soil where feminist therapy took root. From Charlotte Perkins Gilman's harrowing account of the "resting cure" for women's depression in The Yellow Wallpaper (1892) to Phyllis Chesler's now-classic Women and Madness (1972), feminist critics have long exposed sexist biases and abuses in traditional medicine and psychotherapy. Underlying these critiques is an analysis of how power operates between men and women, both in society and in the therapy room.

Research exploring how power is used in the therapeutic relationship is still in the early stages (Horvath \& Greenberg, 1989; Douglas, 1985). Empirical investigations of the feminist therapy process also remain scarce (Worell \& Remer, 1992; Enns, 1993; Worell \& Remer, 2003). The proposed study, an investigation of the power-sharing process in feminist therapy, is an attempt to address these gaps. The egalitarian relationship is a core tenet of the feminist approach, yet power-sharing between feminist therapists and their clients has not been subjected to quantitative research. The current study was designed, therefore, to examine whether therapists who identify as feminist therapists are truly more egalitarian with their clients than therapists who do not identify as feminist therapists. Another long-held assumption among feminist therapists has been that one's identity as a feminist therapist translates into the use of actual feminist therapy 
behaviors, such as assertiveness training or psychoeducation about gender-role socialization. The relationship between feminist identity and feminist behaviors has also been largely neglected by the research (Juntunen et al., 1994; Moradi et al., 2000). Therefore, a second aim of the study is to evaluate this relationship.

This chapter first provides an understanding the origins, theoretical underpinnings, and research on feminist therapy. This overview will present: 1) a survey of the literature on feminist therapy, including its beginnings, critiques of traditional psychotherapy and the contributions it has made to the field of psychology; 2) a working definition of feminist therapy, including the theory behind its practice and its guiding principles, among which the egalitarian relationship occupies a central place; 3) a review of the empirical research on feminist therapy practice, including research on feminist identity and the egalitarian relationship; and 4) the goals of this dissertation study.

\section{Origins of Feminist Therapy}

Although feminist critiques of the mental health establishment have been documented since the late 1800s (Perkins Gilman, 1892; Horney, 1939; de Beauvoir, 1989; Friedan, 1963; Greer, 1971; Chesler, 1972), feminist therapy did not emerge as a distinct therapy approach until the 1970s. The Civil Rights movement of the 1960s, the Stonewall Rebellion in 1969, and the Second Wave of Feminism in the early 1970s created a social climate in which human rights were being re-assessed and pushed forth on multiple fronts (Marecek, 2001). As a result, policies and institutions deemed oppressive were challenged, including practices within the field of psychology. 
Feminist psychologists noted that, before 1970, few articles or books dealt with women's mental health issues (Worell \& Johnson, 2001). For example, major handbooks of psychotherapy published during the 1970s failed to include any chapters related to therapy with women (Worell \& Johnson, 2001). Also missing from the professional dialogue was an attention to gender and the power dynamics perpetuated by adherence to traditional female and male roles (Gilbert, 1980; Gilbert \& Rader, 2001).

This developing awareness of women's invisibility and neglect led to a heightened interest in consciousness-raising, self-advocacy, and activism among women, an interest reflected in the larger culture by such films as The Stepford Wives (1975) and Norma Rae (1979). The emphasis on knowledge-as-power led to a proliferation of consciousness-raising groups, which were aimed at promoting women's solidarity, selfesteem, and assertiveness (Enns, 1993). Consciousness-raising (CR) groups are now considered a precursor to feminist therapy because they embodied a set of values that would eventually be adopted by feminist therapists, values including an attention to women's experiences and roles and an explicit desire to affect social change (Kravetz, Marecek, \& Finn, 1983). A review of studies evaluating the effectiveness of CR groups revealed that the groups were indeed successful in promoting women's self-esteem, autonomy, relationships with other women, an ability to express anger, improvements in interpersonal functioning, and an awareness of societal oppression (Kravetz, 1978).

An increasing number of women therapists entering the field during the $1970 \mathrm{~s}$ built on the successes of CR groups by adopting many of their principles into their own clinical work (Enns, 1993; Lerman, 1987). Therapists who were feminists began to 
examine how their political beliefs and values could more purposefully inform their interactions with clients; in other words, they began a dialogue, both with themselves and with others, as to what a "feminist therapy" might look like (Brown, 2000).

Feminist therapy collectives sprung up throughout the country, from Iowa City, Iowa, to Tulsa City, Oklahoma, and further led to the formation of agencies for victims of rape and domestic violence, "women's" issues that had previously been neglected by the mental health fields (Enns, 1993). In 1982, the Feminist Therapy Institute, a national collective, formed (Brown, 1994; Worell \& Remer, 1992). The institute brought together feminist therapists from many theoretical and training backgrounds for the purposes of supporting feminist work and promoting change within the helping professions. The Feminist Therapy Institute's Code of Ethics, created in 1987 and revised in 1999, is widely used today.

Within counseling psychology, specifically, the formation of Division 17's Committee on Women, following the 1970 APA annual convention, marked the beginning of feminist reforms within that area (Gilbert \& Osipow, 1991).

\section{Feminist Critiques of Traditional Psychotherapy}

Critics within the field of psychology, such as those groups detailed in the aforementioned section, have exposed sexist assumptions in personality theory, diagnosis and treatment, as well as medication abuses and the sexual exploitation of female clients (Chesler, 1972; Gilbert, 1980; Marecek \& Hare-Mustin, 1991). Feminists have also made explicit the everyday gender inequities that produce problems in psychological adjustment and well-being for women (Gilbert, 1980; Marecek \& Hare-Mustin, 1991). 
Furthermore, they have attempted to address gaps in the theoretical and empirical knowledge base about women's experiences, experiences that have been historically invisible, marginalized or pathologized (Brown, 1994; Gilbert, 1980; Worell \& Remer, 1992).

Feminist therapy arose out of these critiques and out of a dissatisfaction with traditional therapies (Brown, 1994; Gilbert, 1980; Worell \& Remer, 1992; Worell \& Johnson, 1997). It has attempted to disrupt the system of male power and entitlement and the ways in which such biases and inequities are perpetuated in therapy (Gilbert, 1980; Worell \& Remer, 1992). Feminist therapists further make a concerted effort to understand how power is used, both outside and inside the therapy room (Douglas, 1985; Hill \& Ballou, 1998; Marecek \& Kravetz, 1998).

Feminist critics from many backgrounds have recognized the need to challenge and change current psychotherapy practices: criticisms have arisen within counseling and clinical psychologies, social work, and psychiatry, and have pervaded all modes of therapy, including individual, couples, family and group modalities.

To summarize, feminist critiques have arisen from many sources and were a response to:

- a need to remedy the invisibility and/or neglect of the full range of women's experiences in psychological theory, research and practice;

- a dissatisfaction with existing theories of female and male development, theories that have positioned males and "male" traits as the psychologically healthy norm;

- a need to expose sex bias in diagnosis and counseling; 
- a desire to end practices of mother-blaming and victim-blaming (e.g., victims of sexual and physical assault);

- a conviction that women's intrapsychic problems can often originate from sources outside of themselves (from sexism, discrimination, abuse, etc.);

- an opposition to the sex-role stereotypes that define femininity for women and masculinity for men as the optimal orientations for psychologically healthy adjustment; and;

- a recognition that many of the reported sex differences in psychological functioning reflect inequalities in social status and power between women and men (Worell \& Remer, 1992).

The emergence of feminist therapy, therefore, marked a revolutionary shift from previous ways of thinking about, and conducting, therapy with women (Worell \& Remer, 1992).

\section{Feminist Therapy's Contributions to Psychological Theory and Practice}

Now in its fourth decade, feminist therapists have generated critiques or revisions of virtually every major mode of therapy (Douglas \& Walker, 1988; Marecek \& HareMustin, 1991). Its principles are currently being integrated into other therapy approaches (Douglas \&Walker, 1988). Feminist psychologists have transformed mental health policy, academic curricula, training programs, and research methodologies (Gilbert \& Osipow, 1991). Feminist therapists come from a wide range of philosophical and theoretical backgrounds and employ many different types of strategies in their therapeutic work (Worell \& Remer, 1992). 
Feminist therapy's focus on the uses of power in the therapeutic relationship has produced important theoretical work regarding the counseling needs of the less powerful members of society - whether they be women, people of color, or gays or lesbians. Feminist psychologists have been at the forefront of establishing gender theory and have promoted a better understanding of the "doing of gender" in therapy (Gilbert \& Scher, 1999; Hare-Mustin and Marecek, 1990). The recognition of gender as a site where power imbalances are particularly evident highlights the importance of assessing the uses of power in the therapeutic relationship.

\section{Gender}

The feminist commitment to examining power in the therapy room has coincided with evolving thinking about sex and gender in counseling and psychotherapy (Brown, 1994). Historically, psychology has followed a gender-as-difference model that emphasizes "essential" differences between women and men and ignores the great degree of overlap between the two sexes (Deaux \& LaFrance, 1998; Gilbert \& Scher, 1999). Early feminist therapists, while challenging many of the biases arising from the genderas-difference model, still focused largely on women's "unique" experiences, issues and qualities (Gilbert \& Osipow, 1991; Enns, 1993). Gilligan's In a Different Voice (1982) is a good example of this "women-are-different-but-equally-valuable" focus. The first feminist therapists worked to create an awareness of "women's problems" such as rape, sexual abuse, and domestic violence, problems that were not being adequately addressed by mainstream therapies and training programs (Enns, 1993). 
The need to transcend the gender-as-difference model, however, and to better understand the sociocultural roots of gendered behavior, soon became apparent (Gilbert \& Scher, 1999; Worell \& Johnson, 1997). Feminist therapists began to recognize the importance of a comprehensive gender theory to guide their research and practice (HareMustin \& Marecek, 1990; Worell \& Johnson, 1997). Worell and Remer (1992) remarked, "Although the call for change rallied around the issues that faced contemporary women, it soon became clear that women's concerns could be reinterpreted in the broader context of gender. That is, researchers in the field hypothesized that behaviors and attitudes previously believed to be determined by sex (female or male) were societally and situationally created rather than intrinsic to the individual" (p. 9). Research emerged to counter prevailing beliefs about sex differences and to provide evidence that differences in power status might better explain sex-related behaviors (Worell \& Remer, 1992). With a greater understanding of gender came a better understanding of the power inequities in society - and in the therapy room. Feminist therapy now positions "gender as a locus for understanding oppression and power imbalance" (Worell \& Johnson, 1997, p. 24).

The current definition of gender thus reflects a more sophisticated awareness of the roles of social forces and power structures in creating and influencing human behavior, and signals a rejection of essentialist explanations of sex differences. Worell and Remer (1992) define gender as “culturally-determined cognitions, attitudes, and belief systems about females and males" (p. 9). Gender is a fluid construct that varies across one's culture, age, and personal views (Worell \& Remer, 1992). Gilbert (1999) 
highlights the ongoing difficulty that traditional psychotherapists have with regard to differentiating between the constructs of gender and sex. This difficulty may arise from the fact that, although gendered behavior is socially determined, gender as a definition is inextricably bound to biological sex as a point of reference. Many practicing therapists still do not endorse the view that sex is a construct separate from gender (Gilbert, 1999), that sex is restricted to a biological label, or whether one is born female or male (Gilbert \& Scher, 1999). For example, a therapist uninformed of current thinking about gender and sex may fail to challenge a female client's subordination of her own needs in relation to those of her husband or family, particularly if s/he assumes that this client is assuming her "natural" role (Gilbert \& Scher, 1999).

In summary, today's feminist practice is informed by an evolving awareness of the historical and ongoing role of gender in women's lives and by shifting parameters of how one defines "gender" and "sex", as well as by longstanding efforts by the Women's Movement to address issues most relevant to female clients (Worell \& Johnson, 1997).

\section{Summary of Feminist Therapy's Contributions}

Feminist therapy has made important contributions to the field of psychology in the areas of theory, research, training, policy and practice (Gilbert \& Osipow, 1991). Its examination of the power mechanisms between men and women has revolutionized the way that power is viewed inside and outside of the therapy room. In particular, feminist therapists have reframed thinking about gender and sex and have been an important voice in the development of theories and practices that address the needs of female clients, as 
well as the needs of other clients who may be marginalized in society. Feminist therapy, in summary, is inclusive therapy.

\section{Feminist Therapy Defined}

\section{A Heterogenous Definition}

Feminist therapy's definition reflects its commitment to inclusiveness and the valuing of all voices. Indeed, there is no "standard" definition of feminist therapy. It is, instead, more of a theoretical orientation than a defined set of procedures or therapeutic models. It has been conceptualized as an approach that transforms other therapies, rather than a separate system parallel to existing ones (Douglas \& Walker, 1988; Marecek, Kravetz, \& Finn, 1979; Gilbert, 1980; Brodsky, 1992). Hill and Ballou (1998) have claimed, "Feminist therapy is not traditional therapy with gender awareness added; it is a complete transformation of the way in which therapy is understood and practiced" (p. 5). Feminist psychologists Marecek and Hare-Mustin (1991) caution against presenting a "false synthesis" of a feminist therapy approach. They instead emphasize the heterogeneity of philosophies and techniques that characterize the approach. In a discourse analysis of feminist therapy, Marecek and Kravetz (1998) came to this conclusion: "Our findings suggest that uniform standards of feminist practice would be nearly impossible to achieve. Just as there is no single definition of feminism nor one kind of feminist, there is no single meaning of feminist therapy, but rather a multiplicity of ideas about principles, processes, and therapy goals" (p. 35).

That being said, current theorists have attempted to offer definitions of feminist therapy that reflect the multi-faceted nature of its practice. Brown (1994) defines 
feminist therapy as "the practice of therapy informed by feminist political philosophy and analysis, grounded in multicultural feminist scholarship on the psychology of women and gender, which leads both therapist and client toward strategies and solutions advancing feminist resistance, transformation, and social change in daily personal life, and in relationships with the social, emotional, and political environment" (p. 22).

\section{Core Tenets}

Given the great diversity that typifies feminist therapy, theorists and practitioners over the past 20 years have recognized the importance of specifying the common themes of the movement (Gilbert, 1980; Enns, 1993; Rosewater \& Walker, 1985; Worell \& Remer, 1992).

In Gilbert's seminal review of the feminist therapy literature (1980), two guiding principles emerged: 1) the personal is political (e.g., client and counselor learn to examine their own values about women and the ways in which those values have been socially constructed); and 2) the therapist-client relationship is egalitarian. The first principle acknowledges the enormous power that society has in telling us "who we are" and highlights the importance of challenging that power. The second principle has particular relevance for the proposed study. According to Gilbert, an egalitarian relationship is achieved when the therapist: 1) views the client as her own expert;2) informs clients of the therapy process and their roles and rights in that process (for example, their right to "shop around" for a therapist and to understand the potential risks of therapy); 3) uses strategies that promote the client's autonomy and power; 4) 
encourages the expression of anger; and 5) models appropriate behaviors for the client (Gilbert, 1980).

Similarly, Marecek and Hare-Mustin (1987) have described three principles they claim typify a feminist orientation to therapy. These include: 1) a consciousness-raising approach, in which clients learn to distinguish between their own problem behaviors and those problems imposed upon them by a sexist culture (similar to Gilbert's "the personal is political"); 2) a woman-validating process, in which clients learn to value their experiences and to recognize their strengths; and 3) an egalitarian relationship, in which clients are encouraged to trust themselves in their therapy and to take an active role in therapeutic work.

Recent research indicates that the list of "core" tenets appears to be growing (Brown, 1994; Worell \& Johnson, 1997). A 12-member therapy group, comprised of many of the leading feminist therapy experts in the field, recently expanded the list to 16 core tenets (Worell and Johnson, 1997). Those foundational principles range from guidelines for ethical psychotherapeutic practice to strategies for sociopolitical analysis (Worell \& Johnson, 1997). Noteworthy in the ever-evolving list of tenets is an increasing awareness of power and the importance of egalitarianism and collaboration, particularly in the therapeutic relationship (Worell \& Johnson, 1997). Six of the 16 core tenets detailed by Worell \& Johnson (1997) reflect this awareness. For example:

- "Feminist therapy is based on the constant and explicit monitoring of the power balance between therapist and client and pays attention to the potential abuse and misuse of power within the therapeutic relationship" (Tenet \#8, p. 69). 
- "Feminist therapy strives toward an egalitarian and non-authoritarian relationship based on mutual respect" (Tenet \#9, p. 69).

- "Feminist therapy is a collaborative process in which the therapist and client establish the goals, direction and pace of therapy" (Tenet \#10, p. 69).

The Egalitarian Relationship

Central to the theoretical work of Gilbert (1980), Marecek and Hare-Mustin (1987), and Worell and Johnson (1997) is an emphasis on egalitarianism between clients and therapists. This emphasis reflects feminism's commitment to analyzing the uses of power in society and understanding how existing power structures deprive women of their autonomy, choices and options (Gilbert, 1980; Worell \& Remer, 1992; Douglas, 1985). In her examination of the power dynamic in feminist therapy, Douglas (1985) wrote, "A feminist critique of psychotherapy has at its root a feminist analysis of sexist society in general. It is suggested that the (traditional) modal therapeutic relationship, one between a male therapist and female client, parallels other patriarchal male/female relationship forms; for example, husband/wife and father/daughter" (p. 241).

How therapists and their clients exercise power is arguably the most salient variable that emerges in discussions of feminist therapy (Marecek \& Kravetz, 1998; Douglas, 1985; Hill \& Ballou, 1998). Power has emerged as the central theme in recent qualitative studies exploring feminist therapy process (Marecek \& Kravetz, 1998; Hill \& Ballou, 1998). Marecek and Kravetz (1998) argued that an examination of power differentials in therapy is a unique feature of feminist therapy. In another study, which involved a survey of 45 feminist therapists, the majority of comments dealt with how 
power impacts the therapeutic relationship (Hill and Ballou, 1998). Hill and Ballou further reported that the importance of collaboration in minimizing power imbalances was a common thread in therapists' assessments of their clinical work.

Marecek and Kravetz (1998) further claim that, before the feminist therapy movement, the mental health establishment failed to adequately deal with issues of power. They argue, "Neither institutionalized psychology nor psychiatry - the primary knowledge bases for most psychotherapy practice - has developed a language for talking about power. Indeed, both have been woefully reluctant to theorize how societal, institutional, or even interpersonal power differences might be connected to psychological distress and disorder" (1998, p. 18).

As described in the aforementioned core tenets of feminist practice, a primary task for the feminist counselor or psychotherapist has been to examine the power differential not only in the client's social world but in the therapy room, as well (Brown, 1994). The hope is that making the power imbalance explicit between therapist and client will create a more egalitarian exchange (Brown, 1994). However, what constitutes an egalitarian exchange may not always be clear. The term "egalitarian relationship" as a description of feminist therapy has been vague and, at times, misleading (Brown, 1994). Brown (1994) claims that "egalitarian" is often misconstrued as the denial of any power differential between therapist and client. However, she argues, "egalitarian" is not synonymous with "equal" in a therapy situation, as some imbalance due to the counselor's expertise is unavoidable and even therapeutic (Brown, 1994). The confusion over the term may reflect the feminist therapist's hyperawareness of and, at times, 
discomfort with her own use of power in the therapeutic relationship. Therapists must perform a difficult balancing act between efforts to restore power to the client while maintaining therapeutic boundaries (Brown, 1994).

Brown defines the egalitarian relationship as:

...one structured to move toward equality of power, in which artificial and unnecessary barriers to equality of power are removed. In this relationship, there is an equality of value and of respect for each person's worth between the participants, but there continues to be some necessary asymmetry in certain aspects of this exchange, in part designed to empower the less powerful person but primarily required to define and delineate the responsibilities of the more powerful one (1994, p. 104).

Worell and Remer (1992) claim that power-sharing is a central concern for feminist therapy because: 1) efforts to minimize the therapist-client power differential reduce the likelihood that therapy will serve as a further means of social control; and 2) the therapist-client relationship should not model the power differentials that women experience outside of the therapy room.

They offer the following strategies for promoting more collaborative therapeutic relationships:

- Therapists should make their values explicit clients, thus giving them the option of rejecting these values;

- Therapists should encourage clients to "shop around" for a therapist;

- Therapists should share their views about society and demystify the therapy process by informing clients of the process, rights, and responsibilities of therapy;

- Therapists should ensure that goals are collaboratively and mutually determined; and 
- Therapists should teach their clients skills that are in accordance with the clients' stated goals.

\section{Research on Feminist Therapy Process}

Despite such efforts to define feminist practice, there has been a paucity of research that examines how feminist therapists interact with their clients, particularly research using quantitive methodologies (Marecek, 2001; Marecek \& Kravetz, 1998; Douglas, 1985). Because egalitarianism is a central tenet of feminist therapy (Brown, 1994; Gilbert, 1980; Marecek \& Hare-Mustin, 1987; and Worell \& Johnson, 1997), it has been targeted as a promising area of research for quite some time (Douglas, 1985; Enns, 1993; Worell \& Remer, 2003). However, despite the great import placed upon the egalitarian relationship in feminist therapy, it has not been quantitatively investigated (Douglas, 1985; Enns, 1993; Worell \& Remer, 1992).

Initial attempts to study feminist therapy focused on client perceptions about feminist therapists rather than on the therapeutic relationship or process (Marecek, Kravetz, \& Finn, 1979; Hackett, Enns, \& Zetzer, 1992). This emphasis was understandable given lingering public perceptions about feminism (e.g., fears that "feminist" means "radical" or "man-hating") and feminist therapy's efforts to gain legitimacy in the field. A pioneering study by Marecek, Kravetz and Finn (1979), for instance, examined whether there were differences between clients who sought out feminist counselors and clients who did not. They demonstrated that clients who selfidentified as feminists were more likely to seek out a counselor with similar feminist values and to rate feminist therapy as more helpful than traditional therapies. Marecek, 
Kravetz and Finn also reported that non-feminist clients reacted favorably to feminist therapy, rating it as equally helpful in comparison to traditional therapies.

Hackett, Enns and Zetzer (1992) also conducted an investigation that compared client reactions to feminist and nonsexist counselors. More specifically, they examined whether clients distinguished between nonsexist, liberal feminist or radical feminist modes of counseling, and whether their responses varied according to their own feminist orientations. Results suggested that perceptions of the liberal feminist counselor were more favorable than those regarding the nonsexist or radical feminist counselors. Findings further indicated that feminist clients, as a whole, were more receptive to all modes of counseling than were nonfeminist clients (Hackett et al., 1992).

Such studies suggest that client responses to feminist therapy have been generally positive (Marecek, Kravetz, \& Finn, 1979; Hackett, Enns, \& Zetzer, 1992). Additional research is needed to further distinguish the differences between feminist, non-sexist, and traditional counseling, as well as client reactions to these approaches (Hackett et al., 1992). In addition, as previously mentioned, very little is known about the actual process of feminist therapy (Enns, 1993).

\section{Definitional Challenges}

There are a number of reasons why research on feminist therapy, particularly feminist therapy process, is scarce. The first set of reasons involves definitional problems. As previously mentioned, to both its detriment and advantage, there is no uniform definition of feminist therapy. Though considerable consensus has been achieved regarding the core tenets of feminist practice, there is no single working 
definition nor set of commonly used practices or techniques, and this presents a challenge for researchers (Hackett, Enns, \& Zetzer, 1992; Marecek and Hare-Mustin, 1991; Marecek and Kravetz, 1998). "This lack of consensus regarding what constitutes feminist therapy has hindered the empirical study of this approach, making it difficult to determine if women therapists actually apply feminist beliefs or use feminist therapy behaviors in therapy with women," several researchers have commented (Juntunen, Atkinson, Reyes \& Gutierrez, 1994). Recall, however, that feminist therapy was never intended to be a separate school of therapy; rather, it was created to transform existing therapies and to create a more inclusive, ethical practice (Marecek, Kravetz, \& Finn, 1979; Gilbert, 1980; Brodsky, 1992).

Another definitional challenge is how one defines a feminist therapist. If a therapist self-identifies as feminist, does that necessarily make her or him a feminist therapist? Or must one examine the therapist's behaviors in order to classify that person as a feminist therapist? As Gilbert and Rossman (1993) point out, there is a tendency to confuse feminist theory with feminist therapy. Can those who engage in "feminist therapy behaviors" (another definitional conundrum) be feminist therapists if they do not identity themselves as such?

In efforts to define a "feminist therapist," most research has relied on self-report (simply asking the person a yes/no question about their feminist identify or assessing their feminist worldview with a measure such as the Feminist Perspectives Scale) and, less frequently, on observer ratings (e.g., the Feminist Family Therapy Behavior Checklist in its original form) (Worell \& Remer, 1992). The most recent attempts to 
label feminist therapists have employed behavioral checklists that assess for such feminist therapy practices as the advocacy of women, power-sharing, and an attention to sociocultural context (Worell \& Johnson, 2001; Moradi et al., 2000; Juntunen et al., 1994). Noteable among these is Judy Worell's work constructing two new measures assessing feminist therapist behaviors, the Therapy with Women Scale (Robinson \& Worell, 1991) and the client version of the scale, the CTWS (Worell, Chandler, \& Robinson, 1996). These measures are particularly relevant to this dissertation project because they emphasize empowerment of the client (Worell \& Johnson, 2001).

Many of these feminist therapy measures are still undergoing the validation process (Worell \& Johnson, 2001; Dankoski, Penn, Carlson \& Hecker, 1998; Juntunen et al., 1994;). The lack of consensus regarding how to define and assess feminist identity and/or feminist therapy behaviors illustrates the need for further exploratory research in these areas (Juntunen et al., 1994). If we do not know how feminist therapists think and behave, a workable definition of "feminist therapist" will remain elusive.

\section{Methodological and Ethical Challenges}

A second set of problems that make it difficult to study feminist therapy empirically involves methodological and ethical concerns. Feminist psychology's efforts to chip away at power differentials between researchers and experiment participants make certain research procedures unfeasible or even unethical (Grossman et al., 1997). Exploiting a participants' contribution without providing her with information that may be beneficial is one example of an unethical research practice (Grossman et al., 1997). In addition, as Hill and Ballou observe (1998), feminist therapists have not engaged in 
empirical research of their own practices "partly because feminist therapy, in contrast to many other therapies (gestalt, cognitive-behavioral, rational-emotive, etc.) is value-driven rather than technique-driven" (p. 3-4). Studying therapy can also be problematic for ethical reasons, and the feminist researcher is vigilant of potential ill effects on clients. Gilbert (1980) noted that the best way to investigate feminist therapy would be to observe actual therapy situations and to systematically analyze them. However, some methods are unfeasible due to sampling difficulties and the possible disruption of the natural therapeutic process (Gilbert, 1980). For this reason, theoretical and qualitative studies of feminist therapy process are more common and remain an indispensable source of knowledge in the field (Marecek, 2001; Marecek \& Kravetz, 1998; Hill \& Ballou, 1998). In conclusion, many factors have contributed to the lack of research examining the egalitarian relationship in feminist therapist - a combination of ethical concerns, definitional ambiguities and methodological challenges. Nevertheless, in order for feminist therapy to gain widespread legitimacy in counseling psychology, studies investigating the process and outcome of its practice are essential. Because an attention to power is a founding principle of feminist therapy, its examination is a logical place to start. Furthermore, since a growing body of research indicates that a client's active participation in therapy is associated with improved outcome, understanding how therapists create collaborative alliances is important for all therapeutic approaches (Eugster \& Wampold, 1996; Orlinsky \& Howard, 1986; Hatcher \& Barends, 1996). 


\section{Goals of this Dissertation Study}

Demonstration of the collaborative relationship in feminist therapy would provide support for what has long been assumed, but not yet empirically validated - that feminist therapeutic alliances are more egalitarian than non-feminist therapeutic alliances. In suggesting directions for future research, Worell and Remer (1992) highlighted the collaborative relationship as a research priority because it overlaps with traditional outcome research on the working alliance and is therefore a logical place to start. Research on the egalitarian relationship in feminist therapy has important implications for the future of its practice and for the practice of psychotherapy, in general. It would shed light on the process of feminist therapy and would help to bolster the legitimacy of its practice in clinical settings and training programs.

Furthermore, ambiguity surrounding the definition of "feminist therapist" warrants the need to examine the link between self-identification as a feminist therapist and the actual use of feminist therapist behaviors. A recent finding that therapists who use feminist interventions may not necessarily identify themselves as feminist therapists demonstrates the need to clarify the label of "feminist therapist," as well as to avoid unsubstantiated assumptions that all feminist therapists engage in feminist therapy practices, and vice versa (Dankoski, Penn, Carlson \& Hecker, 1998).

\section{Goals and Predicted Outcomes}

One goal of the current study was to investigate whether counseling sessions with therapists who identified as feminist therapists were perceived by clients to be more egalitarian than counseling sessions with therapists who did not identify as feminist 
therapists. More specifically, it was predicted that client ratings of both power-sharing and treatment collaboration, as assessed by self-report measures, would be higher for those paired with therapists who identified as feminist therapists than for those paired with therapists who did not identify as feminist therapists. A second goal was to provide empirical evidence for another common, but largely unsupported, claim of feminist therapy - that one's identification as a feminist therapist would be related to one's use of actual feminist therapy behaviors, particularly those behaviors aimed at empowering the client. Early studies have demonstrated a link between feminist identity and behaviors (Juntunen et al., 1994; Moradi et al., 2000). The proposed study was expected to provide additional support for these findings. 


\section{METHOD}

Procedure

Data was collected after at least six sessions between counseling dyads. Six sessions is considered to be an adequate amount of time in which to establish a therapeutic alliance (Lambert \& Hill, 1994). Perceptions of the working alliance carry over across multiple sessions (Brossart et al., 1998), such that assessment after the sixth session will be representative of perceptions of the collaborative working alliance as a whole. Counselor/client dyads were involved in ongoing (as opposed to terminated) therapeutic relationships.

The study was limited to female participants in order to avoid a sex of therapist and/or sex of client confound. Volunteers were solicited via university counseling centers, the investigator's training program, the Feminist Therapy Institute, and Division 35 (Psychology of Women) of the American Psychological Association. Specifically, volunteers were solicited from four university counseling centers in the greater Austin area (Austin, San Marcos and Georgetown) and in Philadelphia. The investigator obtained names and e-mail addresses of therapists from counseling center staff lists, which were listed on center websites. Colleagues associated with the investigator's department, including counseling trainees, were also contacted by the investigator via email. Members of the Feminist Therapy Institute, a national organization of feminist therapists, were approached in person by the investigator at the institute's annual meeting (November 2002 in Boston, MA). Additional participants were approached via the Division 35 listserv via a participant recruitment ad. (See Appendix A). 
With the exception of those therapists approached in person (see above), all therapists were contacted via personal e-mail addresses or the aforementioned listserv. All therapists were informed that their help was being solicited to investigate the relationship between a therapist's theoretical approach and perceptions of the therapeutic relationship. Once a therapist chose to participate, she was provided with the study materials by the investigator via mailed packets that included separate, stamped return envelopes for both therapists and clients. Therapist volunteers then approached a female client of their choosing. She informed her client of the study and asked her if she would be interested in participating. Refer to Appendix B to view instructions to therapists, including the suggested method for approaching client volunteers. Clients were provided with the same rationale for the study. Once clients agreed to participate, they were provided with the study materials by their therapists. See Appendix C to view instructions to the client volunteers. A signed, informed consent form meeting criteria established by the Departmental Review Committee and the University Institutional Review Board was obtained from all participants, and all participants were invited to contact the investigator if they had any questions or concerns. See Appendix D for a copy of the participant consent form.

After meeting for at least six sessions, both therapists and clients completed questionnaires, individually, in separate rooms. Therapists were asked to fill out a demographics questionnaire and four self-report instruments, one assessing their identity as a feminist therapist (yes/no), one assessing their use of feminist therapy behaviors, one assessing their level of power-sharing with clients, and one assessing feminist 
perspective. In addition, therapists were asked to provide a response explaining their answers to the feminist self-identification question.

Clients were asked to complete a demographics questionnaire and two self-report instruments, one assessing their perceptions of the collaborative relationship with their therapists, and one assessing their perceptions of therapist power-sharing. Clients were also asked whether they identified themselves as feminists, and whether they identified their therapists as feminist therapists.

All therapists and clients were invited to request a copy of the study write-up. Therapists will be provided with a report of the study results, which they can share with interested clients. All manner and methods involving the solicitation of volunteers, informed consent, and data collection followed the ethical standards for research with human participants, as outlined by the American Psychological Association and the University Institutional Review Board.

\section{Participants}

\section{Therapists}

Participants were 42 practicing female therapists from the various groups and locations described above. Participating therapists were asked to complete a brief background information form that assessed for age, marital status, race/ethnicity, estimated annual income, etc. (see Appendix C). Therapist mean age was 40 years $($ Range $=24-71$, Median $=38$, $\mathrm{SD}=12.40$, ). With regard to marital status, $45.2 \%$ were married, $38.1 \%$ were single, and $16.7 \%$ were in a committed partnership. The sample was predominantly Caucasian (85.7\%); remaining participants were African American (7.1\%); Latina (4.8\%); or other 
races/ethnicities $(2.4 \%)$. All participating therapists returned their study materials by the stated deadline. Therapists were encouraged to complete their materials as soon as possible after meeting with their clients for at least six sessions, and informed that all materials had to be received by the investigator by May 31, 2003, the deadline established by the Institutional Review Board for the completion of all data collection activities.

With regard to education level, 50\% had master's degrees, 45.2\% had Ph.D.s and $4.8 \%$ had bachelor's degrees. The mean number of years of clinical experience was 12.45 $(\mathrm{SD}=8.83$, Range $=1-40$ years $)$. Mean number of hours a week seeing clients was $16.49($ Median $=10, \mathrm{SD}=8.90)$. Specialty areas included counseling psychology (47.6\%), clinical psychology $(42.9 \%)$, social work $(7.1 \%)$, or some other mental health field $(2.4 \%)$. Therapists practiced in a variety of settings, including college counseling centers $(33.3 \%)$, private practice $(28.6 \%)$, community mental health agencies $(19 \%)$, university clinics $(9.5 \%)$, or some combination of the aforementioned settings $(9.5 \%)$.

With regard to annual income, $35.7 \%$ reported earning less than $\$ 25,000,31 \%$ between $\$ 25,000$ and $\$ 50,000,19 \%$ between $\$ 50,000$ and $\$ 74,000,9.5 \%$ between $\$ 75,000$ and $\$ 100,000$, and $4.8 \%$ more than $\$ 100,000$. The relatively high percentage of therapists in the lower income bracket likely reflects the fact that participants included trainees.

Therapists were also asked to estimate the percentage of their clients who were women (See Therapist Information Form, Appendix E). Mean reported percentage of female clients was $80.36 \%(\mathrm{SD}=16.16)$. 
Of the 42 therapists who participated, 25 (59\%) self-identified as feminist therapists and $17(41 \%)$ did not.

\section{Clients}

Participants were 34 clients, all female. Client number was smaller than therapist number because eight clients opted not to participate along with their therapists. The therapists of these eight clients were not informed by the investigator that their clients did not mail their study materials back to the investigator. The investigator chose not to inform therapists so as to disrupt the natural therapeutic relationship as little as possible. The investigator also wanted to avoid potential ill effects to clients (e.g., fear of negative evaluation by therapists) that could have arisen if their failure to follow through with participation was reported.

Participating clients were asked to complete a brief background information form that assessed for age, marital status, race/ethnicity, estimated annual income, etc. (See Appendix F.) Clients'mean age was 35.76 years $($ Range $=19-59, \mathrm{SD}=11.91$ ). Most clients were single $(67.6 \%) ; 26.5 \%$ were married and $5.9 \%$ were in a committed partnership (5.9\%). The sample was predominantly Caucasian (79.4\%), with 5.9\% identifying as African American, 5.9\% as Latina, 2.9\% as Asian American and 5.9 as other races/ethnicities.

With regard to education level, 38.2\% had bachelor's degrees, 29.4\% had high school diplomas, 20.6\% had master's degrees, 2.9\% had Ph.D.s, and 8.8\% had some other type of professional degree. Regarding income, $36.4 \%$ reported earning less than $\$ 25,000$ a year, $39.4 \%$ between $\$ 25,000$ and $\$ 50,000,9.1 \%$ between $\$ 50,000$ and 
$\$ 74,000,12.1 \%$ between $\$ 75,000$ and $\$ 100,000$, and $3.0 \%$ more than $\$ 100,000$. The relatively high percentage of participants in the lower income bracket likely reflects the fact that many volunteer clients were students.

Length of time in counseling with current therapist averaged 15.94 months $($ Range $=1$ month to 7 years, Median $=12, \mathrm{SD}=15.47)$. Mean hours per week in therapy was $1.14($ Median $=1$ hour a week, Range $=$ half hour to 3 hours week, SD $=.56)$. Total length of time in therapy (with current and previous therapists) was 47.53 months $($ Median $=27$ months, Range $=3$ months -23 years, $S D=54.85)$. Clients reported receiving counseling at a variety of settings, including private practices $(44.1 \%)$, college counseling centers $(41.2 \%)$, community mental health agencies $(11.8 \%)$, or some combination of the aforementioned settings (2.9\%).

Of the 34 clients who participated, 19 (55\%) self-identified as feminist and 15 self-identified as non-feminist. Sixteen clients out of the 34 who participated (47\%) identified their therapists as feminist therapists. Slightly more than half of the clients, 19(56\%), "accurately" identified their therapists as either feminist or non-feminist when responses were matched with those of their therapists. Of the 15 clients (44\%) who inaccurately identified their therapists, most (nine, or 60\%) believed their feminist therapist was a non-feminist therapist.

Clients' own feminist identities had little impact on their ability to label therapists accurately (eight of participants who disagreed identified themselves as feminist, whereas seven of those who disagreed identified themselves as non-feminist). 


\section{Measures}

\section{Therapist Measures}

Therapists completed measures assessing for feminist therapist identity, feminist perspectives, feminist therapy behaviors, and power-sharing behaviors.

\section{Feminist Therapy Identity}

Therapists were asked to provide a yes-or-no response to the question, "Do you identify yourself as a feminist therapist?" No description of a feminist therapist was provided. Responses to this question were used to classify therapists as either selfidentified or not self-identified as a feminist therapist for the purposes of data analysis and hypothesis testing.

Therapists were also asked to provide a response to an open-ended question ("Briefly explain your answer to the above question.") in order to assess whether participant conceptualizations of feminist therapy matched with or differed from those described in the current feminist therapy literature. See Appendix G for a copy of these questions.

\section{Therapist's Feminist Perspective}

The Feminist Perspectives Scale (Henley, Meng, O'Brien, McCarthy, \& Sockloskie, 1998). See Appendix H. The Feminist Perspectives Scale was created to assess the range of diverse feminist attitudes. It includes six attitudinal subscales: conservative, liberal, radical, socialist, cultural feminist, and women of color. Each subscale includes 10 attitudinal items to which participants respond using a 7-point Likert scale, which ranges from 1 (strongly agree) to 7 (strongly disagree). For example, the 
liberal perspective subscale includes such items as, "People should define their marriage and family roles in ways that make them feel most comfortable" and "The government is responsible for making sure that all women receive an equal chance at education and employment" (p. 346). Instructions to respondents were, "Indicate your level of agreement, using this scale, for the following items. Write the corresponding number after each item."

Reliability: The composite of the five feminist subscales (omitting conservative scale), Femscore, is a good overall measure of feminist attitudes towards women and is the measure used in this study. Henley et al. (1998) reported a Cronbach alpha of .91 for Femscore, and test-retest correlations of .91 at two weeks and .86 at four weeks. Coefficient alpha for Femscore in the current study was .93.

Validity: Henley et al. (1998) correlated subscales of the FPS with participant religiosity, political stance, feminist identity, and whether of not they had taken a women's studies course, and reported that Femscore correlated significantly with these variables.

Feminist Therapy Behaviors

The Feminist Therapy Behavior Checklist (Juntunen, Atkinson, Reyes \& Gutierrez, 1994). See Appendix I. Juntunen, Atkinson, Reyes and Gutierrez (1994) modified the Feminist Family Therapy Behavior Checklist (Chaney \& Piercy, 1988) in two ways that make it a useful instrument for the proposed study: 1) they converted it from an observer measure to a self-report measure; and 2) they reworded items focusing exclusively on family therapy to fit an individual therapy context. 
The modified version of the checklist, renamed the Feminist Therapy Behavior Checklist (FTBC), includes 37 items that range from "As a therapist, I try to underline female client's competence" to "As a therapist, I try to educate clients regarding the inequality of status and power between the sexes" (Juntunen et al., 1994, p. 329). Therapists are asked to use a 5-point Likert scale $(1=$ never to $5=$ always $)$ to indicate how often they employ each specific behavior included on the checklist. Instructions were, "Indicate your level of agreement, using this scale, for the following items. Write the corresponding number after each item."

The Feminist Family Therapy Behavior Checklist is one of only two measures of feminist therapy behavior in existence (Worell \& Robinson, 1993) and it is the bestvalidated (Chaney \& Piercy, 1988; Dankoski et al., 1998; Juntunen et al., 1994; Moradi et al., 2000). The total score of the modified version was used in this study. Juntunen et al. (1994) reported a mean item score of $3.99(\mathrm{SD}=.43)$ for therapists who identified as feminists. Moradi et al. (2000) have further reported a mean item score of 3.78 (SD = .63) for feminist therapists working with female clients and a mean item score of 3.72 $(\mathrm{SD}=.63)$ for feminist therapists working with male clients.

Reliability: Juntunen et al. (1994) reported a coefficient alpha of .93 for the FTBC. Chaney and Piercy (1988), developers of the pre-modified version, reported good internal consistency (using a Kuder-Richardson formula of .92). In the current study, the coefficient alpha was .95 .

Validity: Dankoski et al. (1998) have demonstrated that self-identified feminist therapists endorse the checklist's feminist therapy behaviors to a greater degree than 
those who do not self-identify as feminist therapists. Chaney and Piercy demonstrated good construct validity with the measure in its original form (1988).

\section{Power-Sharing Behaviors}

Therapy with Women Scale (Robinson \& Worell, 1991). See Appendix J. The Therapy with Women Scale (TWS) was constructed from an "intensive review of the principles, beliefs, and strategies reported in the feminist therapy literature" (Worell \& Johnson, 2001). It includes 40 declarative statements (e.g., "In my counseling and psychotherapy with clients, I establish an egalitarian relationship..."), to which participants respond using a 7-point Likert scale $(1=$ almost never true, $7=$ almost always true). Respondents are instructed, "For each of the following statements, decide to what degree it describes your approach to counseling and psychotherapy with women. Then write the number in the space to the left of each statement that best describes your approach to working with women clients." Scale authors report that the measure was created to differentiate feminist therapy from other therapeutic styles. In initial studies with the TWS, conducted with a sample of 266 practitioners, two factors - empowerment and advocacy for women - emerged that differentiated feminist-identified clinicians from nonfeminist-identified clinicians (Robinson, 1994). The total scale score was used for the current study to assess power-sharing behaviors.

Reliability: Scale authors report an internal reliability of .89- .91 (Robinson \& Worell, 1991). In the current study, coefficient alpha was .94.

Validity: Robinson (1991) reported that the TWS correlates significantly with a measure of client empowerment (the Personal Progress Scale, Worell \& Chandler, 1996). 


\section{Client Measures}

\section{Therapist Power-Sharing}

Client Therapy with Women Scale (Worell, Chandler \& Robinson, 1996). See Appendix K. The Client Therapy with Women Scale (CTWS) contains selected items from the aforementioned Therapy with Women Scale, reworded to reflect client perceptions of therapist power sharing. Clients are asked to decide "to what degree each statement describes your experience in these counseling sessions." The scale contains 28 items to which clients respond using a 5-point Likert scale that ranges from 1 (not at all true) to 5 (frequently true). Statements on the scale include, "In my counseling session, my counselor established an egalitarian relationship with me." and "supported me in making life changes.'The scale contains 28 items rated on a 5-point Likert scale, which include such statements as, "In my counseling sessions, my counselor established an egalitarian relationship with me" and "In my counseling sessions, my counselor supported me in taking charge of my life."

Reliability: In the current study, the CTWS had a coefficient alpha of .86.

Validity: Scale authors report that in a study of 45 counseling dyads, only four of the 28 items differed significantly between therapist TWS and client CTWS (Worell, Chandler, Robinson, \& Cobulius, 1996).

\section{Therapist Collaboration with Client on Treatment}

The Working Alliance Inventory - Client Form (Horvath \& Greenberg, 1989). See Appendix L. The Client Form of the Working Alliance Inventory (WAI-C) is a 36-item, self-report measure that assesses the quality of the therapeutic relationship as perceived 
by the client. The WAI is arguably the most widely used measure of both the working alliance and therapeutic relationships in general (Hill, Nutt \& Jackson, 1994). The WAI is based on Bordin's (1980) three-part (bond, goal, task), pantheoretical conceptualization of the therapeutic alliance. The measure therefore contains three subscales: development of a bond, agreement on goals, and agreement on tasks. Each of these subscales is represented by 12 items rated on a 7 -point Likert-type scale $(1=$ never, $7=$ always $)$. Respondents are instructed, "Rate your level of agreement with the following statements about your therapist. Select a number from the choices above and write it beside the statement."

Taken as a total score, the WAI was designed to measure perceived levels of collaboration between counselor and client. According to the measure's developers, Horvath and Greenberg (1989), "Bordin's concepts of bond, goal and task involve collaboration and hinge on the degree of concordance and joint purpose between the counselor and client" (p. 224). Example items include, " (Counselor name) and I collaborate on setting goals for my therapy," and "(Counselor name) and I are working towards mutually agreed upon goals." The total WAI score will be used for statistical analysis.

Reliability: The WAI-C has good internal consistency. A coefficient alpha of .93 was reported for the WAI-C (Horvath \& Greenberg, 1989). In the present study, the coefficient alpha was .89 . 
Validity: The WAI's developers have reported that the WAI composite score is predictive of a client's reported outcome after three sessions (Horvath \& Greenberg, 1989). 


\section{Hypotheses}

1. Counseling dyads with self-identified feminist therapists will receive higher client ratings of (a) power-sharing (CTWS) and (b) collaboration (WAI-C) than dyads with non-feminist therapists.

2. Self-identified feminist therapists will report engaging in a greater number of (a)

power-sharing behaviors (TWS) and (b) feminist therapy behaviors (FTBC) than nonfeminist therapists. 
Results

The results are presented in three main sections. The first section presents findings on the study's two main hypotheses. The second section describes the correlational pattern among the various continuous variables included in the study. The third section describes responses to the open-ended question therapists completed describing why they did or did not self-identify as a feminist therapist and how their responses corresponded to the theoretical literature.

\section{Tests of the Main Hypotheses for Therapists and Clients}

One-tailed t tests were used to assess the hypothesized relationship between therapist feminist identity (yes/no) and therapist measures of power-sharing (TWS), feminist therapy behaviors (FTBC), and feminist perspective (FPS). T tests were also used to assess the hypothesized relationship between therapist feminist identity (yes/no) and client measures of therapist power-sharing (CTWS) and treatment collaboration (WAI-C). Item means and standard deviations are summarized in Table 1 and tests performed are summarized in Table 2.

\section{Therapists}

Power-sharing. As hypothesized, participants who identified as feminist therapists were more likely to report on the TWS that they used power-sharing behaviors with their clients $(M=5.52)$ than those who did not identity as feminist therapists $(M=$ 5.04) $(t(32)=-1.94, p=.03)$. Although both groups described power-sharing to be characteristic of their approach to therapy, those who self-identified as feminist therapists did so to a significantly greater extent. 
Feminist therapy behaviors. Participants who self-identified as feminist therapists $(M=4.08)$ did not differ from those who $\operatorname{did}$ not $(M=3.89)$ in their reported use of feminist therapy behaviors on the Feminist Therapy Behavior Checklist $(t(32)=-.16, p=$ .44). Therapists in both categories described themselves as frequently engaging in the behaviors on the checklist.

Feminist perspective. Participants who self-identified as feminist therapists $(M=$ 5.51) indicated greater agreement with feminist attitudes as assessed by the Feminist Perspectives Scale than those therapists who did not identify as feminist therapists $(M=$ 4.98) $(t(32)=-2.17, p=.02)$. Therapists in both categories indicated that they somewhat agreed (e.g., $5=$ somewhat agree) with the items on the FPS, but those who identified as feminist therapists were more likely to endorse feminist attitudes.

\section{Clients}

Power-sharing. As hypothesized, clients paired with therapists who identified as feminist therapists reported a greater number of power-sharing behaviors on the part of their therapists $(M=3.78)$ than clients paired with therapists who did not identify as feminist therapists $(M=3.43)(t(32)=-1.97, p=.03)$. Clients in both categories rated their therapists as engaging in power-sharing behaviors more often than not, but clients of feminist-identified therapists reported these behaviors to be more frequent.

Treatment collaboration. Clients paired with therapists who identified as feminist therapists $(M=6.41)$ did not differ from clients paired therapists who did not identify as feminist therapists $(M=6.13)$ in their ratings of treatment collaboration $(t(32)=-1.58 p$ $=.06)$. Clients in both categories rated their therapists as being collaborative. 


\section{Table 1}

Item Means and Standard Deviations, Therapist and Client Measures for Participants in the Two Categories

\begin{tabular}{|l|l|l|l|l|l|l|}
\hline & $\begin{array}{l}\text { Total } \\
(\mathrm{n}=34)\end{array}$ & & $\begin{array}{l}\text { Self-Identified } \\
\text { Feminist } \\
\text { Therapists } \\
\text { and their Clients } \\
(\mathrm{n}=19)\end{array}$ & & $\begin{array}{l}\text { Therapists not } \\
\text { Self-Identified } \\
\text { as Feminist } \\
\text { Therapists and } \\
\text { their Clients } \\
(\mathrm{n}=15)\end{array}$ & \\
\hline Variable & $M$ & $S D$ & $M$ & $S D$ & $M$ & $S D$ \\
\hline $\begin{array}{l}\text { Client } \\
\text { Measures }\end{array}$ & & & & & & \\
\hline CTWS & 3.63 & .54 & 3.78 & .53 & 3.43 & .50 \\
\hline WAI-C & 6.29 & .51 & 6.41 & .37 & 6.13 & .63 \\
\hline $\begin{array}{l}\text { Therapist } \\
\text { Measures }\end{array}$ & & & & & & \\
\hline TWS & 5.30 & .74 & 5.51 & .76 & 5.04 & .63 \\
\hline FTBC & 4.00 & .57 & 4.08 & .60 & 3.89 & .52 \\
\hline FPS & 5.28 & .74 & 5.51 & .62 & 4.98 & .79 \\
\hline
\end{tabular}

Note. CTWS $=$ Client Therapy with Women Scale; ratings were made on a 5-point scale; WAI-C = Working Alliance Inventory - Client Form; ratings were made on a 7-point scale; TWS = Therapy with Women Scale; ratings were made on a 7-point scale; FTBC $=$ Feminist Therapy Behavior Checklist; ratings were made on a 5-point scale; FPS = Feminist Perspectives Scale; ratings were made on a 7-point scale.

\section{Table 2}

Results of One-Tailed T Tests Comparing Self-Identified Feminist Therapists and Therapists Not Self-Identified as Feminist Therapists and their Clients

\begin{tabular}{|l|l|l|}
\hline Variable & $t$ & $p$ \\
\hline Client Measures & & \\
\hline CTWS & -1.97 & .03 \\
\hline WAI-C & -1.58 & .06 \\
\hline Therapist Measures & & \\
\hline TWS & -1.94 & .03 \\
\hline FTBC & -.98 & .17 \\
\hline FPS & -2.17 & .02 \\
\hline
\end{tabular}

Note. $\mathrm{n}=34$ to 42; CTWS = Client Therapy with Women Scale; WAI-C = Working Alliance Inventory Client Form; TWS $=$ Therapy with Women Scale; FTBC Total $=$ Feminist Therapy Behavior Checklist; FPS $=$ Feminist Perspectives Scale. 


\section{Intercorrelations Among the Measures}

Pairwise analyses using Pearson's r were used to assess the relationship between all continuous variables of power-sharing, collaboration, feminist therapy behaviors, and feminist perspective (TWS, CTSW, WAI, FTBC, FPS). Age of client, age of therapist, and therapist clinical experience (years of practice) were included in the correlational analyses. (See Table 3.)

\section{Relationship Between Client and Therapist Measures of Power-Sharing}

Client reports of therapist power-sharing (CTWS) correlated significantly with therapist reports of power-sharing (TWS) $(r=.30, p=.05)$, offering some support for the claim that these scales are measuring the same construct. The relationship between the two instruments also suggests that clients are cognizant of their therapists' attempts to foster more egalitarian relationships with them.

Relationships Between Power-Sharing, Feminist Therapy Behaviors, and Feminist Perspective

Therapist reports of power-sharing (TWS) were significantly correlated with feminist therapy behaviors (FTBC). $(r=.76, p=.00)$. Therapist reports of power-sharing also correlated significantly with therapists' describing themselves as taking a feminist perspective (FPS) $(r=.29, p=.05)$. One would expect a relationship between powersharing and feminist therapy behaviors, and the demonstrated correlation offers additional support for the validity of these measures. 


\section{Relationships Between Therapist Age, Experience, and Behaviors}

Therapist age and experience were related to the measures of therapist behaviors. Power-sharing behaviors as assessed by the therapists was significantly related to therapist age $(r=.45, p=.00)$ and years of clinical experience $(r=.51, p=.00)$. Therapists' reported use of feminist therapy behaviors was also significantly related to therapist age $(r=.56, p=.00)$ and years of experience $(r=.50, p=.00)$. In addition, client assessments of therapist power-sharing correlated significantly with therapist experience $(r=.36, p=.01)$. These relationships between therapist age, experience, and behaviors, while not surprising, are interesting and worthy of further exploratory research.

\section{Additional Comments}

The absence of a correlation between the measure of treatment collaboration (WAI-C) and the other measures suggests that this instrument may be assessing a different dimension of the therapy experience.

Overall, the low intercorrelations between the variables of interest in the main hypotheses (e.g., CTWS, WAI-C) offer some support for the claim that significant differences on the tests of hypotheses did not arise because the instruments were measuring the same aspects of the therapy experience. 


\section{Table 3}

Intercorrelations Between Therapist Age, Experience, and Client and Therapist Measures

\begin{tabular}{|l|l|l|l|l|l|l|l|}
\hline Variable & 1. & 2. & 3. & 4. & 5. & 6. & 7. \\
\hline $\begin{array}{l}\text { 1. Therapist } \\
\text { Age }\end{array}$ & - & $.75^{* *}$ & .16 & .06 & $.45^{* *}$ & $.56^{* *}$ & -.02 \\
\hline $\begin{array}{l}\text { 2. Therapist } \\
\text { Experience }\end{array}$ & $.75^{* *}$ & - & $.36^{*}$ & .04 & $.51^{* *}$ & $.50^{* *}$ & .16 \\
\hline 3. CTWS & .16 & $.36^{*}$ & - & .24 & $.30^{*}$ & .14 & -.23 \\
\hline 4. WAI-C & .06 & .04 & .24 & - & .12 & .02 & -.03 \\
\hline 5. TWS & $.45^{* *}$ & $.51^{* *}$ & $.30^{*}$ & .12 & - & $.75^{* *}$ & $.29^{*}$ \\
\hline 6. FTBC & $.56^{* *}$ & $.50^{* *}$ & .14 & .02 & $.75^{* *}$ & - & .17 \\
\hline 7. FPS & -.02 & .16 & -.23 & -.03 & $.29^{*}$ & .17 & - \\
\hline
\end{tabular}

Note. $\mathrm{n}=34$ to 42; CTWS = Client Therapy with Women Scale; WAI-C = Working Alliance Inventory Client Form; TWS $=$ Therapy with Women Scale; FTBC Total $=$ Feminist Therapy Behavior Checklist Total Score; FPS $=$ Feminist Perspectives Scale. ${ }^{*} p=<.05,{ }^{*} p=<.01$.

\section{Analyses of Therapist Responses to the Open-Ended Question}

An important aspect of this research was the examination of whether participant descriptions of feminist therapy included those tenets named in the literature. Seven representative articles and book chapters were sampled in order to identify core tenets.

Authors were chosen based on widely recognized expertise in the area of feminist therapy (Gilbert, 1980; Marecek \& Hare-Mustin, 1987; Worell \& Remer, 1992, Brown, 1994; Wyche \& Rice, 1997; Hill \& Ballou, 1998; Worell \& Johnson, 2001).

Sampling of these sources produced five major tenets:

- attention to client empowerment/egalitarian stance (named by all sources) 
- attention to sociocultural context (e.g., awareness of gender roles, considerations of culture in case conceptualization, etc.) (named by all sources)

- valuing of women's experiences (named by four sources)

- commitment to social change (named by three sources)

- client-centered approach (client-affirming, strengths-based) (named by two sources)

Hence, only two tenets emerged that were universally named: attention to power and attention to sociocultural context.

\section{Coding of Therapist Responses}

The researcher then coded therapists' responses using these two tenets, and compared responses with those of two trained raters. A response was judged as including one or both tenets if at least two of the three raters coded the response accordingly. Instructions to trained raters are detailed in Appendix L. Coding procedures followed guidelines for dependability suggested by experts in qualitative research (Lincoln \& Guba, 1985; Hill, Thompson, \& Nutt Williams, 1997). Percentage agreement between coders was .87 (Rater 1 and Rater 2) and .80 (Rater 1 and Rater 3).

Of the 25 feminist therapist-identified therapists who participated in this study, 23 provided a response when prompted, "Briefly explain your answer to the above question (Do you identify yourself as a feminist therapist?)”. Of the 17 non-feminist-therapistidentified therapists who participated, 14 provided responses. 


\section{Tenet \#1: Attention to Power}

Coding of the open-ended questions indicated that therapists who identify as feminist therapists differ from therapists who do not identify as feminist with regard to how they describe their clinical work. In particular, the feminist therapists in this study were more likely to mention an attention to power when asked to explain why they defined themselves as feminist therapists (60 percent of feminist therapists, compared to 18 percent of non-feminist therapists). Following are excerpts from four therapist descriptions of their clinical work:

I think being a feminist therapist means envisioning a collaborative relationship between myself and client, means recognizing that we each bring our own knowledge (both lived and academic), means acknowledging that we each have valid ways of knowing, but that ultimately my clients will guide our sessions. More than defining the content of what we discuss, feminist therapy to me defines a process of client empowerment to make decisions, identify strengths, (and) form connected relationships (for which our therapeutic relationship is a model).

I believe in and conduct therapy with the philosophy of love, compassion, and respect -feminist values. I strive towards an egalitarian relationship (although, by nature of the therapy setting, it seldom is equal to the client), and overcoming oppression.

I value and work towards egalitarian relationships, attempt to be aware of my own use and misuse of power as a white female therapist, facilitate clients' looking at the context of their culture and gender as they interpret their lives, urge valuing one's experience and knowledge, see political action by myself and those I affect as basic to changing systems of oppression, believe undoing racism as central to this change, (and) believe gender as a definition to be highly relevant to all aspects of experience.

I prioritize considerations of power and oppression in my relationship with clients, my understanding of the etiology of human pain, and my approaches to alleviating that pain.

Hence, analyses of the open-ended questions supports data from the quantitative 
measures that therapists who identify as feminist therapists are more likely to attend to issues of power with their clients. Furthermore, the therapist explanations contain hints of why egalitarianism is a priority. For some, sharing power is a sign of respect; for others, it is an acknowledgment that the client brings valuable knowledge to the treatment.

Furthermore, the egalitarian relationship is oftentimes viewed as a corrective experience for clients who have been oppressed as a result of sexism, racism, etc.

\section{Tenet \#2: Attention to Sociocultural Context}

With regard to the second tenet, feminist-identified therapists were also more likely to mention an attention to sociocultural context in their explanations, when compared to non-feminist-identified therapists (52 percent compared to 24 percent). For example, one feminist therapist explained:

I make use of explicitly feminist models which take into account sociocultural and economic forces at work in individuals' lives, and modify other theories, models and techniques so that they are compatible with this underlying approach. For me, feminist therapy is both a way of understanding human behavior in its social context, and a way of interacting with clients that has the potential to effect profound change in both the client and the community (as well as the therapist).

Another therapist described a process of :

...considering with the client the impact of learned sex roles in family in addition to the effect of socialization on current difficulties and choice-making. (I) deeply value that questioning stereotypes is optimal for the client and that empowering her/him around these and other issues is good for society as a whole.

For both of these therapists, attending to the client's unique socioeconomic world when considering their difficulties was also a means of changing the larger society. 


\section{Discussion}

An attention to power dynamics, both in society and in the therapy room, has been a hallmark of feminist therapy since its inception in the 1970s (Gilbert, 1980; Marecek \& Hare-Mustin, 1987; Worell \& Remer, 1992, Brown, 1994; Wyche \& Rice, 1997; Hill \& Ballou; Worell \& Johnson, 2001). However, there have been no published quantitative studies demonstrating this critical aspect of its practice. The current study is the first of its kind to offer support for the long-assumed but previously unsupported claim that feminist therapists create more egalitarian relationships with their clients when compared to their non-feminist counterparts.

Results offered partial support for the two major hypotheses. Specifically, findings indicated that: 1) self-identified feminist therapists were more likely to report engaging in power-sharing behaviors with their clients than therapists who did not identify as feminist therapists: and that 2) clients paired with self-identified feminist therapists were more likely to report power-sharing behaviors on the part of their therapists. These results are consistent with early and as yet unpublished research that has employed the same measures of power-sharing (Worell \& Johnson, 2001).

Qualitative data gleaned from therapists' written descriptions of their theoretical orientations supported the quantitative findings. Specifically, the participants who selfidentified as feminist therapists in this study were more likely to mention an attention to power than their counterparts when asked to explain why they identified themselves as feminist therapists. Reasons given for adopting an egalitarian stance varied, with some therapists viewing it as a way to validate the client's own expertise and others viewing it 
as a way to disrupting larger, societal systems of oppression. An attention to power was viewed, therefore, not just as a means of transforming the individual but of transforming sociocultural factors that contribute to client distress.

Results did not support the hypothesized relationship between therapist feminist identity and the reported use of feminist therapy behaviors, nor the hypothesized relationship between therapist self-definition and client ratings of treatment collaboration. However, findings did suggest a trend of clients reporting greater collaboration if paired with identified feminist therapists $(\mathrm{t}=-1.58, \mathrm{p}=.06)$, a trend that may have proven significant with a larger sample size. Previous research has demonstrated a link between feminist identity and the use of feminist therapy behaviors (Moradi et al., 2000; Juntunen et al., 1994). However, it is important to note that such studies have explored the link between one's identity as a feminist and one's behaviors, as opposed to one's identity as a feminist therapist and behaviors. More research is needed to tease apart these subtle but important identifications.

\section{Implications for Feminist Therapy Research and Practice}

This investigation has addressed a need for research providing empirical support for feminist therapy's aims and practices, research considered by many to be essential to increasing its profile in graduate programs and applied settings (Brown \& Brodsky, 1992; Worell \& Johnson, 1997; Marecek, 2001). Furthermore, demonstration of the egalitarian relationship in feminist therapy provides support for the claim that feminist therapy involves a process of client empowerment, a process that has been neglected in the mainstream literature. The egalitarian relationship has long been targeted as a research 
priority by feminist therapists (Worell \& Remer, 1992; Douglas, 1985), both because it is a central tenet of feminist therapy and because collaborative working alliances are associated with client reports of improvement (Orlinsky \& Howard, 1986; Hatcher \& Barends, 1996).

This study attempted to address another gap in the research on feminist therapy, regarding the link between feminist identity and behaviors. Ambiguity surrounding the term "feminist therapist" highlights the need to examine the relationship between selfidentification as a feminist and how such beliefs get translated into interventions (Dankoski et al., 1998). There is a need to clarify what the label of "feminist" means to most practicing therapists, and a danger of assuming that feminist identity automatically translates into feminist therapy behaviors (or that non-feminist therapists do not employ feminist interventions). Although the quantitative findings offer support that selfidentified feminist therapists are more likely to report power-sharing behaviors with their clients, results related to other feminist therapy behaviors, as measured by the Feminist Therapy Behavior Checklist (e.g., engaging in psychoeducation about gender roles), were inconclusive.

The qualitative data sheds some light on how feminist-identified therapists might differ from non-feminist-identified therapists. A content analysis of the feminist therapy literature revealed that two factors are universally named as being integral to feminist practice: an attention to considerations of power and an attention to sociocultural context. Therapists' descriptions in this study of why they either defined themselves as feminist or non-feminist supported this research, in that feminist therapists were more likely to 
explicitly mention these two factors when compared to non-feminist therapists. An ethic of fairness and a commitment to social justice infused many of the feminist therapists' remarks, and what most distinguished their descriptions from those of the non-feminist therapists was an active consciousness regarding societal power dynamics and a strong desire not to perpetuate those dynamics in the therapy room.

Some remarks by participants who did not label themselves as feminist therapists also reflected a desire for gender fairness and equality; however, these therapists were less likely to describe an attention to power dynamics or an effort to locate a client's distress within a larger sociocultural context. Furthermore, although some therapists expressed support for feminist values, they did not view feminism, specifically, as a means of helping their clients. For example, one participant wrote, "I am striving to be a feminist in thoughts and values, but I have not defined my mission as a therapist in terms of helping women in society. I have defined it in terms of my spirituality and wish to enhance all others, i.e., men and women.”

Comments of participants who did not self-identify as feminist therapists fell into three broad groups: those therapists who preferred not to label themselves with any particular theoretical orientation; those therapists who expressed discomfort with the term "feminist"; and those therapists who identified themselves as open to feminist values but who did not specifically label themselves as "feminist therapists." The decision to reject the label of "feminist therapist" was motivated, therefore, by a number of reasons, reasons which may have combined to make the variable of power less salient in the therapy room. 


\section{Summary of Implications}

Results from the current study thus have several meaningful implications. As mentioned previously, demonstration of the egalitarian relationship in feminist therapy may help to bolster the legitimacy of its practice and provide a power-sharing model for therapists of all therapy orientations. In addition, further exploration of what it means to be a "feminist therapist" might help to promote feminist therapy's efforts to further demystify the process of psychotherapy, add a level of clarity to feminist training and supervision, and encourage research initiatives examining feminist therapy practice.

\section{Study Limitations}

A small sample size of therapists $(n=42)$ and clients $(n=34)$ limits generalizability of this study's results. Therefore, data reported here is not necessarily representative of all feminist therapists or non-feminist therapists. However, the significant findings with such a small sample sizes does suggest that the issue of power-sharing is quite salient among feminist therapists and their clients, highlighting its potential for additional research.

Self-selection of participants is another limitation of this and many other studies assessing clinical practices. Recruitment of participants for this research was challenging, as one would expect when one is attempting to study actual therapy situations. The investigator solicited volunteers, some of whom were known to the investigator, so findings may not be reflective of therapists as a whole. Therapists are, to their credit, protective of their clients, and both therapists and clients are reluctant to subject what is a very private experience to empirical research. Therefore, in the current study, great 
efforts were made to protect the therapy relationship. For example, therapists were given much latitude with regard to choosing which of their clients to approach and when to approach them, and great care was taken to ensure that clients would not feel pressured to participate. If a therapist expressed any hesitation about participation after being approached by the investigator, the investigator encouraged her to ask questions and to ultimately follow her own judgment with regard to what was best for her client and for the therapeutic relationship.

Relatedly, the decision to allow therapists to select a client of her choosing could have potentially introduced bias into the findings. Once again, the effort to balance research ethics with rigorous design was a challenging one; what may be best for the design may not be best for the participants, and this is an important and ever-thorny issue in the field of counseling psychology research.

Another sample limitation was the decision to exclude male therapists and clients from the study. As mentioned earlier, the decision was made in order to eliminate a confound due to sex. Much has been written about gender, sex, and their relationship to interpersonal power dynamics (See Review of the Literature). The investigator wanted to help ensure that any perceived differences in power-sharing on the part of participants were due to differences in therapeutic practices rather than differences due to personal factors, such as one's gender role.

This study was further limited by the availability of suitable measures with which to measure power-sharing. Instruments assessing this aspect of clinical practice are 
virtually nonexistent, such that the researcher was led to employ newer scales, such as the Therapy with Women scale.

\section{Directions for Future Research}

Further studies are needed, with larger samples, to quantitatively evaluate the impact of feminist therapist identity on power-sharing and on therapy outcome. This study did not investigate client satisfaction or progress in achieving their goals. Qualitative studies might further illuminate the relationship between therapists' feminist identity and their commitment to building more egalitarian relationships with clients. Although an attention to power has been a longstanding feature of feminist therapy, little is known about what draws some therapists to a feminist approach, how therapists internalize an ethic of egalitarianism, how they apply this ethic to practice, and how their clients perceive such attempts to involve them more actively in the therapeutic process.

This study also highlights the need for the development of additional instruments to assess the uses of power in therapy. Because a growing body of research suggests that treatment collaboration is key to client improvement, better measuring and understanding how such collaboration occurs is a worthwhile endeavor (Eugster \& Wampold, 1996;

Orlinsky \& Howard, 1986; Hatcher \& Barends, 1996). Judith Worell's ongoing efforts to develop and validate measures of feminist therapy process are especially promising (Worell \& Johnson, 2001).

Finally, this study's findings indicated relationships between therapist years of practice and both therapist and client ratings of power-sharing. More research is needed 
to explore these relationships. Do therapists become more egalitarian as they gain more experience, both in their personal lives and in the therapy room?

\section{Closing Remarks}

A common response to a description of feminist therapy is, "But isn't that just good therapy?" (Brown, 1992). Feminist therapists have irrevocably changed the way therapy is practiced, and perhaps those changes are leading to increasingly subtle differences between feminist therapists and non-feminist therapists.

Now in its third decade, feminist therapy has led to improved sex fairness in diagnosis, treatment, and theory. Feminist therapists have also been the voice for the historically voiceless survivors of domestic and sexual abuse, sexual harassment and sexual discrimination. Feminist researchers and theorists have questioned the ethics and validity of traditional scientific methods. They have created and promoted gender theory and new ways of thinking about "male" and "female." Finally, they have helped shape counseling ethics and public policy.

Feminist therapy is more of a transformative approach than a separate school of clinical practice, and feminists are now represented among all the major theoretical orientations. But despite its pervasive impact, feminist therapy remains "on the fringe" in training programs and counseling settings. Brown (1992) has observed, "It is not that feminist therapy itself has moved into the mainstream. Rather, we have acted as a powerful gadfly, moving the mainstream away from destructive dominant paradigms and into new visions that are shaped by feminist analysis" (p. 56). 
In particular, the feminist movement has highlighted the need to attend to inequities in society and in mental health practices of all theoretical orientations. Studying the use of power is thus relevant for all forms of therapy, not just those therapies practiced by feminists. Power abuses in psychotherapy have been of critical concern since the inception of the "talking cure" (Chesler, 1972; Douglas, 1985). For example, sexual misconduct with clients remains a major reason for litigation targeting therapists (Pope, 1994). Furthermore, the recent expansion of counseling ethical codes, other highly publicized lawsuits targeting therapists, and changing notions of authority in contemporary society necessitate a greater understanding of the uses of power with clients. 


\section{Appendix A}

\section{PARTICIPANTS NEEDED FOR STUDY OF THERAPY PROCESS}

Female participants are needed for a study assessing the relationship between a therapist's theoretical orientation and perceptions of the therapeutic process. The study is brief and non-intrusive.

Female therapist participants will be asked to fill out questionnaires taking approximately 30 minutes to complete. They will also be asked to approach one female client and ask her to fill out a set of questionnaires, which will take approximately minutes to complete. The study has been carefully designed to minimize potential disruptions to the natural therapeutic process. All responses will remain confidential, and all participants, both therapists and clients, will be provided with study results if they are interested.

Participants need to have met (or will meet) with their client at least 6 times in order to participate. Degree type of therapist is unimportant (e.g., social workers, psychologists, psychiatrists, etc.). The study is also open to trainees.

The researcher is a Counseling Psychology doctoral student completing dissertation work at the University of Texas at Austin. This study has been approved by the Institutional Review Board.

For further information and/or to participate in this study, please contact Jill Rader at rader@mail.utexas.edu or 512-698-5529. Thank you! 


\section{Appendix B}

\section{Therapist Instructions}

Therapists and clients may complete their questionnaires at any point after they have met for at least six sessions. It is important that therapists and clients complete their questionnaires in separate rooms. Therapists and clients do not have to complete their questionnaires at the same time, but they should complete their questionnaires on the same day. For example, clients may opt to complete their questionnaires in the waiting room after a session, and therapists may complete their own questionnaires in their offices at this time or at a later time.

\section{Presenting questionnaires to client:}

Assure your client that participation in this study will not negatively impact your therapeutic relationship with her, and that you have no stake in her choice to either participate or to decline participation. Her participation is entirely voluntary.

In addition, assure her that her responses will remain confidential, to be viewed only by the Principal Investigators. Tell her she will be provided with a stamped, selfaddressed envelope in which to seal her completed questionnaires, and that she will need to sign the sealed flap of the envelope so that the Principal Investigators will be assured that the data remains confidential. Given these safeguards, present her with the option of leaving her sealed, signed envelope for you to mail if she is comfortable with that and finds it to be more convenient.

Inform your client that completion of the questionnaires will take approximately 30 minutes and that further instructions will be included in her packet of questionnaires.

\section{Completing your own questionnaires:}

You are also being provided with a stamped, self-addressed envelope in which to seal your questionnaires. Additional instructions are included on the individual questionnaires. Your questionnaires should take approximately 30 minutes to complete. Once you have completed your questionnaires, mail them to the Principal Investigators as soon as possible.

Thank you for your participation in this study! 


\section{Appendix C}

\section{Client Instructions:}

Please read the following consent form and sign it if you want to participate in this study. One copy is yours to keep.

Please complete the following questionnaires. They should take approximately 30 minutes to complete. After you have finished them, put them in the manila envelope provided (along with your signed consent form), seal the flap, and write your signature over the flap to assure that your answers will be seen only by the researchers. You may either mail the envelope yourself or leave it with your therapist to mail if that option feels comfortable to you.

Thank you for your participation in this study! 


\section{Informed Consent to Participate in Research}

\section{The University of Texas at Austin}

You are being asked to participate in a research study. This form provides you with information about the study. The Principal Investigator (the person in charge of this research) will also describe this study to you and answer all of your questions. Please read the information below and ask questions about anything you don't understand before deciding whether or not to take part. Your participation is entirely voluntary and you can refuse to participate without penalty or loss of benefits to which you are otherwise entitled.

\section{Title of Research Study:}

Therapist and Client Perceptions of the Therapy Process.

\section{Principal Investigators:}

Jill Rader, MIJ, and Lucia A. Gilbert, Ph.D.

Department of Educational Psychology, The University of Texas at Austin.

Contact phone number: (512) 494-0663 (Jill Rader).

\section{Funding source:}

Jill Rader.

\section{What is the purpose of this study?}

The purpose of this study is to investigate the relationship between a therapist's approach to therapy and both therapist and client perceptions of the counseling process. Data will be collected from a total of 80 therapist/client pairs.

\section{What will be done if you take part in this research study?}

You will be asked to complete several questionnaires assessing your perceptions of the therapy process. Questionnaires should take no more than 45 minutes to complete. 


\section{What are the possible discomforts and risks?}

No physical, social or legal risks are anticipated as a result of participation in this study.

Potential psychological effects may include fears surrounding a loss of confidentiality with regard to therapist and/or client responses. In addition, clients may perceive that therapists are pressuring them to participate in the study and that they must comply or else risk displeasing their therapists. Clients may also fear that their participation in the study may negatively impact the therapeutic relationship. Similarly, therapists may fear being "evaluated" by their clients, as well as by the researcher. They may also experience anxiety as a result of asking their clients to participate in this study, and may fear possible negative impact upon the therapeutic relationship.

These potential psychological risks will be addressed in the following ways: all answers will remain confidential (e.g., therapists will not see client responses, and clients will not see therapists responses). The identity of the participants will be known only to the researcher, and all questionnaires and data will be stored in a locked file cabinet in the researcher's home office. All participants will be assigned codes prior to data entry to ensure that they cannot be identified or linked to specific responses.

There may be additional risks that are unknown at this time. Treatment will not be provided in the event that participation in this study causes psychological distress. Clients participating in this study are encouraged to discuss any resulting distress from this study with their therapists, or to contact the principal investigators for assistance in getting a referral in their area. Similarly, therapists participating in this study are invited to contact the principal investigators should they experience psychological distress and need referral assistance.

If you wish to discuss the information above or any other risks you may experience, you may ask questions now or call the Principal Investigator listed on the front page of this form.

\section{What are the possible benefits to you or to others?}

Participation in this study may prompt therapists and clients to discuss their working relationship more explicitly, thus potentially promoting a stronger therapeutic bond. On a larger scope, your participation in this research may help to illuminate and demystify the therapeutic process, such that mental health professionals and those in graduate psychology training programs can better address those aspects of clinical work that are most beneficial to clients.

\section{If you choose to take part in this study, will it cost you anything?}

There are no costs associated with this study. 
Will you receive compensation for your participation in this study?

No compensation is offered for your participation in this study.

\section{What if you are injured because of the study?}

There are no physical risks associated with this study.

\section{If you do not want to take part in this study, what other options are available to you?}

Participation in this study is entirely voluntary. You are free to refuse to be in the study, and your refusal will not influence current or future relationships with The University of Texas at Austin.

\section{How can you withdraw from this research study?}

If you wish to stop your participation in this research study for any reason, you should contact Jill Rader at (512) 494-0663. You are free to withdraw your consent and stop participation in this research study at any time without penalty or loss of benefits for which you may be entitled. Throughout the study, the researchers will notify you of new information that may become available and that might affect your decision to remain in the study.

In addition, if you have questions about your rights as a research participant, please contact Clarke A. Burnham, Ph.D., Chair, The University of Texas at Austin Institutional Review Board for the Protection of Human Subjects, 512/232-4383.

\section{How will your privacy and the confidentiality of your research records be protected?}

Authorized persons from The University of Texas at Austin and the Institutional Review Board have the legal right to review your research records and will protect the confidentiality of those records to the extent permitted by law. If the research project is sponsored then the sponsor also have the legal right to review your research records. Otherwise, your research records will not be released without your consent unless required by law or a court order.

If the results of this research are published or presented at scientific meetings, your identity will not be disclosed. 
Will the researchers benefit from your participation in this study?

The researchers will not benefit from your participation in this study beyond publishing or presenting results (at which time your identity will not be disclosed).

\section{Signatures:}

As a representative of this study, I have explained the purpose, the procedures, the benefits, and the risks that are involved in this research study:

Signature and printed name of person obtaining consent

You have been informed about this study's purpose, procedures, possible benefits and risks, and you have received a copy of this Form. You have been given the opportunity to ask questions before you sign, and you have been told that you can ask other questions at any time. You voluntarily agree to participate in this study. By signing this form, you are not waiving any of your legal rights.

Printed Name of Subject

Date

Signature of Subject

Date

Signature of Principal Investigator

Date 


\section{Appendix E}

\section{Therapist Information Form}

Please provide the following information. Your answers will remain confidential.

Age:

Marital Status:

Race/Ethnicity:

Estimated annual income:

Academic Degrees/Licenses Earned :

Years of professional experience as a counselor or psychotherapist:

Average number of hours spent per week conducting counseling/therapy sessions:

Specialty area (check one):

Clinical Social Work

Counseling Psychology

Clinical Psychology

Other (please specify):

Type of setting in which you currently practice (college counseling center, private practice):

Estimated percentage of clients who are women: 


\section{Appendix F}

\section{Client Information Form}

Please provide the following information. Your answers will remain confidential.

Age:

Marital Status:

Race/Ethnicity:

Estimated annual income:

Highest level of education attained (for example, high school, some college, college degree, post-graduate degree):

How long have you been seeing your current therapist?:

Average number of hours you spend per week in counseling/psychotherapy sessions (including individual, couples, and/or group sessions):

Estimated total length of time spent in current and all previous counseling/psychotherapy sessions (for example, in weeks, months, years):

What reason or reasons brought you to therapy?

Type of setting in which you currently receive counseling/psychotherapy (college counseling center, private practice):

Would you describe your counselor/psychotherapist as a feminist therapist? (yes/no):

Would you describe yourself as a feminist? (yes/no): 
Appendix G

\section{Therapist Self-Identification as a Feminist Therapist}

Do you define yourself as a feminist therapist? (yes/no)

Briefly explain your answer to the above question: 


\section{Appendix $\mathrm{H}$}

\section{Feminist Perspectives Scale}

Indicate your level of agreement, using this scale, for the following items. Write the corresponding number after each item.

\begin{tabular}{|c|c|c|c|c|c|}
\hline $\begin{array}{l}\mathbf{1} \\
\text { strongly } \\
\text { disagree }\end{array}$ & $\begin{array}{l}2 \\
\text { moderately } \\
\text { disagree }\end{array}$ & $\begin{array}{l}\mathbf{3} \\
\text { somewhat } \\
\text { disagree }\end{array}$ & $\begin{array}{l}4 \\
\text { undecided }\end{array}$ & $\begin{array}{l}5 \\
\text { somewhat } \\
\text { agree }\end{array}$ & $\begin{array}{l}6 \\
\text { moderately } \\
\text { agree }\end{array}$ \\
\hline
\end{tabular}

1. Given the way that men are, women have a responsibility not to arouse them by their dress and actions.

2. Pornography exploits female sexuality and degrades all women.

3. In education and legislation to stop rape, ethnicity and race must be treated sensitively to ensure that women of color are protected equally.

4. Women should not be direct participants in government because they are too emotional.

5. Whether one chooses a traditional or alternative family form should be a matter of personal choice.

6. People should define their marriage and family roles in ways that make them feel most comfortable.

7. The government is responsible for making sure that all women receive an equal chance at education and employment.

8. Racism and sexism make double the oppression for women of color in the work environment.

9. Prostitution grows out of the male culture of violence and male values of social control.

10. Capitalism and sexism are primarily responsible for the increased divorce rate and general breakdown of families.

11. Replacing the word "God" with "Goddess" will remind people that the deity is not male.

12. Women of color have less legal and social service protection from being battered than White women have.

13. A man's first responsibility is to obtain economic success, while his wife should care for the family's needs.

14. Men should follow women's lead in religious matters, because women have a higher regard for love and peace than men.

15. Using "man" to mean both men and women is one of many ways sexist language destroys women's existence.

16. Sex role stereotypes are only one symptom of the larger system of patriarchal power, which is the true source of women's subordination.

17. Homosexuals need to be rehabilitated into normal members of society. 
18. The workplace is organized around men's physical, economic, and sexual oppression of women.

19. Men's control over women forces women to be the primary caretakers of children. 20. Making women economically dependent on men is capitalism's subtle way of encouraging heterosexual relationships.

21. Women of color are oppressed by White standards of beauty.

22. The availability of adequate child care is central to a woman's right to work outside the home.

23. The breakdown of the traditional family structure is responsible for the evils in our society.

24. Homosexuality is not a moral issue, but rather a question of liberty and freedom of expression.

25. A socialist restructuring of businesses and institutions is necessary for women and people of color to assume equal leadership with White men.

26. Being put on a pedestal, which White women have protested, is a luxury that women of color have not had.

27. Social change for sexual equality will best come about by acting through federal, state, and local government.

28. Putting women in positions of political power would bring about new systems of government that promote peace.

29. Men use abortion laws and reproductive technology to control women's lives.

30. Traditional notions of romantic love should be replaced with ideas based on feminine values of kindness and concern for all people.

31. Romantic love supports capitalism by influencing women to place men's emotional and economic needs first.

32. By not using sexist and violent language, we can encourage peaceful social change.

33. Legislation is the best means to ensure a woman's choice of whether or not to have an abortion.

34. Men prevent women from becoming political leaders through their control of economic and political institutions.

35. Beauty is feeling one's womanhood through peace, caring, and nonviolence.

36. It is a man's right and duty to maintain order in his family by whatever means necessary.

37. Women's experience in life's realities of cleaning, feeding people, caring for babies, etc., makes their vision of reality clearer than men's.

38. The world is a more attractive place because women pay attention to their appearance and smiles.

39. The way to eliminate prostitution is to make women economically equal to men.

40. Antigay and racist prejudice act together to make it more difficult for gay male and lesbian people of color to maintain relationships.

41. Capitalism hinders a poor woman's chance to obtain adequate prenatal medical care or an abortion.

42. Women should try to influence legislation in order to gain the right to make their own decisions and choices. 
43. In rape programs and workshops, not enough attention has been given to the special needs of women of color.

44. Rape is best stopped by replacing the current male-oriented culture of violence with an alternative culture based on more gentle, womanly qualities.

45. It is the capitalist system which forces women to be responsible for child care.

46. Marriage is a perfect example of men's physical, economic, and sexual oppression of women.

47. Women should not be assertive like men because men are the natural leaders on earth.

48. Romantic love brainwashes women and forms the basis for their subordination.

49. Discrimination in the workplace is worse for women of color than for all men and White women.

50. Bringing more women into male-dominated professions would make the professions less cut-throat and competitive.

51. Much of the talk about power for women overlooks the need to empower people of all races and colors first.

52. Women should have the freedom to sell their sexual services.

53. Using "he" for "he or she" is convenient and harmless to men and women.

54. All religion is like a drug to people and is used to pacify women and other oppressed groups.

55. Rape is ultimately a powerful tool that keeps women in their place, subservient to and terrorized by men.

56. Capitalism forces most women to wear feminine clothes to keep a job.

57. The tradition of Afro-American women who are strong family leaders has strengthened the Afro-American community as a whole.

58. The personalities and behaviors of "women" and "men" in our society have developed to fit the needs to advanced capitalism.

59 . Heterosexuality is the only natural sexual preference.

60. Men need to be liberated from oppressive sex role stereotypes as much as women do. 


\section{Appendix I}

\section{Feminist Therapy Behavior Checklist}

Indicate your level of agreement, using this scale, for the following items. Write the corresponding number after each item.

\begin{tabular}{llllc}
\hline 1 & 2 & 3 & 4 & 5 \\
never & infrequently & sometimes & frequently & always
\end{tabular}

As a therapist, I...

1.Educate clients regarding the inequality of status and power between the sexes.

2.Reframe a male's abusive behavior (e.g., incest or battering) as conforming to society's promotion of male violence.

3.Raise sex-role issues whether or not clients bring them up.

4.Introduce sex-role issues when dealing with family of origin problems.

5.Discuss the differential impact of divorce on men and women.

6.Reframe the client's definition of the problem to include the impact of socialization.

7.Challenge the client's definition of the problem to include the impact of socialization.

8.Re-educate clients about roles that are oppressive to both men and women.

9.Challenge clients to develop more egalitarian relationships.

10.Suggest alternative sex-role behaviors to clients.

11.Assist clients to negotiate a more equal distribution of child-rearing tasks.

12.Assist clients to negotiate a more equal distribution of household tasks.

13.Indicate that individual well-being should not be sacrificed to preserve relationships.

14.Offer non-sexist hypotheses to explain family problems.

15.Hold male and female clients equally responsible for change in heterosexual

partnerships.

16.Challenge both male and female clients to adopt both instrumental and expressive behaviors.

17.Assist female clients to become involved in status-related activities.

18.Assist clients to develop network supports that will be encouraging of anticipated sex role changes.

19.Support the client's moves to expand beyond traditional sex-role behaviors.

20.Enhance the self-esteem of female clients by focusing on their unique and

positive contributions.

21.Emphasize a female client's competence.

22.Support a female client's decision-making abilities.

23.Encourage female clients to be more assertive.

24.Encourage female clients in heterosexual relationships to develop their own social 
support networks rather to rely on male partners for support.

25.Assist female clients to identify, and deal with, possible patterns of dependency.

26.Support competence in women in both traditional and non-traditional roles.

27.Assist a female client to negotiate for her own personal area in or outside of her home.

28.Assist a female client to negotiate for her own personal time within relationships.

29.Educate female clients about assertive and functional ways of expressing anger.

30.Employ role-plays to help clients integrate new sex-role behaviors.

31.Teach female clients to assess and meet their own needs.

32.Teach male clients to recognize and express their feelings.

33.Teach male clients to better meet the emotional and nurturing needs of their partners and/or families.

34.Model both instrumental and expressive behaviors.

35.Clearly communicate my own sex-role values.

36.Assume a collaborative stance with the client.

37.Encourage clients to assess their own change and growth. 
Appendix $\mathbf{J}$

\section{TWS}

For each of the following statements, decide to what degree it describes your approach to counseling and psychotherapy with women. Then write the number in the space to the left of each statement that best describes your approach to working with women clients.

\section{Almost never true}

1

2
Sometimes true

3
4
Almost always true

5

6

\section{In my counseling and psychotherapy with clients, I:}

1. Establish an egalitarian relationship with my client.

2. Explain my theoretical orientation to my client during the first session.

3. Negotiate goals for treatment with my client.

4. Discuss the expected course of treatment (e.g., how long our work might take, how we can assess progress, etc.)

5. Disclose my values, when appropriate, to my client.

6. Support my clients in taking charge of their lives.

7. Encourage my clients to actively state their needs to me and others in their lives.

8. Disclose personal experiences relevant to my client's issues.

9. Help my clients to trust their feelings and experiences.

10. Believe women have a subordinate status in our culture.

11. Consider my clients as experts on their experiences, thoughts, and feelings.

12. Indicate to my clients that their problems should be considered through a gender role perspective.

13. Support and value my female clients' relationships with other women.

14. Encourage my clients to work actively for social change as it impacts on women's improved status.

15. Actively explore a woman's sense of self-identity apart from other people.

16. Suggest to my clients that differences between women and men are predominantly the result of socially constructed gender roles.

17. Routinely ask my clients about physical or sexual abuse occurring in the present or in the past.

18. Encourage some of my clients to consider a group experience as well as individual therapy.

19. Affirm and validate my clients' current and past accomplishments.

20. Encourage my clients to participate in activities that nourish them.

21. Share with my clients the environmental input to their expressed problems. 
22. Address skills my clients may need to deal with others in their lives as they make changes.

23. Directly identify myself as a feminist in my interactions with clients and other professionals.

24. Explore ways to help my clients be safe in their environment.

25. Recommend books and readings that may be helpful for my clients.

26. Support my clients in exploring issues related to their sexuality.

27. Adjust my fees on a sliding scale as needed according to my clients' financial status.

28. Am sensitive to, and address with my clients the special issues of gender, minority or ethnic status, race, disability, and sexual orientation.

29. Believe women clients are generally better helped by women therapists.

30. Model feminist actions and thoughts for my clients.

31. Work actively for social change as it impacts on women's improved status.

32. Believe psychiatric diagnostic labels are frequently gender-biased against women.

33. Encourage multiple options for my clients at all stages of their lives.

34. Am aware of, and encourage the use of, auxiliary supports for my clients, such as women's centers, rape crisis centers, battered women's centers, community mental health centers, gay-lesbian groups.

35. Am careful to screen resources (e.g., medical doctors, lawyers, etc.) regarding their attitudes towards women before I refer my women clients.

36. Am aware of current information regarding issues as they affect clients such as reproductive health, substance abuse, risk of acquiring HIV, etc.

37. Am committed to working with clients who experience discrimination and subordination in our culture.

38. Am actively involved in political or professional organizations which address the needs of oppressed or under-served populations.

39. Provide feminist supervision to other mental health professionals.

40. Have provided workshops, seminars, academic classes, or other education on issues directly pertaining to gender. 
Appendix K

\section{Counseling Experience}

(CTWS)

For each of the following statements, decide to what degree it describes your experience in these counseling sessions. Then select on of the five answers that best describes your agreement or disagreement with the statement and write the number in the space before each statement.

\begin{tabular}{lllll} 
Not at & Seldom & Cannot & Sometimes & Frequently \\
all true & true & say & true & true \\
1 & 2 & 3 & 4 & 5 \\
\hline
\end{tabular}

\section{In my counseling sessions, my counselor:}

1. Established an egalitarian relationship with me.

2. Explained her theoretical orientation to me during the first session.

3. Negotiated with me about goals for treatment.

4. Discussed the expected course of treatment (e.g., how long our work might take, how we can assess progress, etc.).

5. Disclosed some personal values to me.

6. Supported me in taking charge of my life.

7. Encouraged me to actively state my needs in counseling and to others in my life.

8. Disclosed personal experiences relevant to my issues.

9. Helped me to trust my feelings and experiences.

10. Believes women have a subordinate status in our culture.

11. Considered me as an expert on my own experiences, thoughts and feelings.

12. Suggested that my problems could be considered through a gender role perspective.

13. Supported my relationships with other women.

14. Encouraged me to work actively for social change as it impacts on women's improved status.

15. Actively explored my sense of self-identity apart from other people.

16. Suggested that differences between women and men are predominantly taught by society.

17. Asked me about physical or sexual abuse occurring in the present or in the past.

18. Encouraged me to consider a group experience as well as individual therapy.

19. Affirmed and validated my current and past accomplishments.

20. Encouraged me to participate in activities that nourish me.

21. Shared with me how my environment contributed to my expressed problems. 
22. Addressed skills I may need to deal with others in my life as I make changes. 23. Directly identified herself as a feminist in my counseling sessions. 24. Explored ways to help me feel safe.

25. Recommended books or readings related to my issues in counseling. 26. Encouraged me to explore issues related to my sexuality. 27. Adjusted counseling fees according to my resources.

28. Encouraged me to consider issues related to my culture or ethnicity. 
Appendix L

\section{Working Alliance Inventory (Client Form)}

\begin{tabular}{|c|c|c|c|}
\hline ever & $\begin{array}{l}2 \\
\text { almost never }\end{array}$ & $\begin{array}{l}3 \\
\text { occasionally }\end{array}$ & $\begin{array}{l}4 \\
\text { sometimes }\end{array}$ \\
\hline
\end{tabular}

Rate your level of agreement with the following statements about your therapist. Select a number from the choices above and write it beside the statement:

Your

rating:

1. I feel uncomfortable with (therapist's name).

2. improve my situation.

3. I am worried about the outcome of my sessions.

4. What I am doing in therapy gives me new ways of looking at my problem.

5. and I understand each other.

6. perceives accurately what my goals are.

7. I find what I am doing in therapy confusing.

8. I believe likes me.

9. I wish and I could clarify the purpose of our sessions.

10. I disagree with

11. I believe the time about what I ought to get out of therapy. and $I$ are spending together is not spent

efficiently. 12. does not understand what I am trying to accomplish in therapy.

13. I have a clear understanding of my responsibilities in therapy.

14. The goals of these sessions are important to me.

15. I find what and I are doing in therapy is unrelated to my

concerns.

16. I feel that the things I do in therapy will help me to accomplish my goals.

17. I believe is genuinely concerned for my welfare.

18. I am clear as to what wants me to do in these sessions.

19. and I respect each other.

20. I feel that is not totally honest about her feelings toward me.

21. I am confident in 's ability to help me.

22. and I are working towards mutually agreed-upon goals.

23. I feel that appreciates me.

24. We agree on what is important for me to work on.

25. As a result of these sessions, I am clearer as to how I might be able to change.

26. and I trust each other.

27. and I have different ideas on what my problems are.

28. My relationship with is very important to me. 
29. I have the feeling that if I say or do the wrong things, will stop working with me.

30. and I collaborate on setting goals for my therapy. 31. I am frustrated by the things I am doing in therapy.

32. We have established a good understanding of the kind of changes that would be good for me.

33. The things that is asking me to do don't make sense.

34. I don't know what to expect as a result of my therapy.

35 . I believe the way we are working with my problem is the right one. 36. I feel cares about me even when I do things that she does not approve of. 


\section{Appendix M}

\section{Instructions to Coders}

\section{PHASE ONE: PRACTICE AND TRAINING}

Lucia suggests that we begin by practicing our coding on the eight therapists who do not have clients. These are: 1T, 8T, 16T, 19T, 20T, 35T, 36T, 40T. Let's start with the first four, compare notes via phone/email, then practice on the last four and compare notes via phone/email.

Here's how we'll practice:

Create a simple checklist (two columns) with the following two categories and indicate whether responses fit.

A) Focus on Power (e.g., maintains collaborative/egalitarian stance with clients, advocates for equality in society, etc.)

B) Attention to Sociocultural Context (e.g., awareness/discussion of gender roles, analysis of oppression, considering socialization and culture in case conceptualization, the personal is political, etc.)

For example, for Therapist $\mathrm{X}$, you might put a check mark under the power column but not under the context column.

\section{2) PHASE TWO: CODING THERAPIST DATA}

Code the therapist data we will actually use (remaining 34 therapists) with the same checklist described above. 


\section{Bibliography}

Brossart, D. F., Willson, V. L., Patton, M. J., Kivlighan, D. M., \& Multon, K. D. (1998). A time series model of the working alliance: A key process in short-term psychoanalytic counseling. Psychotherapy, 35 (2), 197-205.

Brown, L. S. (1990). The meaning of a multicultural perspective for theory-building in feminist therapy. Women \& Therapy, 9 (1-2), 1-21.

Brown, L. S. (1994). Subversive dialogues: Theory in feminist therapy. New York: Basicbooks.

Brown, L. S., \& Brodsky, A. M. (1992). The future of feminist therapy. Psychotherapy, $29(1), 51-57$.

Chaney, S. E., \& Piercy, F. P. (1988). A feminist family therapist behavior checklist. American Journal of Family Therapy, 16 (4), 305-318.

Chesler, P. (1972). Women and madness. Garden City, N.Y.: Doubleday.

Dankoski, M. E., Penn, C. D., Carlson, T. D., \& Hecker, L. L. (1998). What's in a name? A study of family therapists' use and acceptance of the feminist perspective. American Journal of Family Therapy, 26 (2), 95-104.

De Beauvoir, S. (1989). The second sex. New York: Vintage.

Douglas, M. A. (1985). The role of power in feminist therapy: A reformulation. In L. B. Rosewater \& L. E. Walker (Eds.), Handbook offeminist therapy: Women's issues in psychotherapy (pp. 241-249). New York: Springer Publishing.

Dutton-Douglas, M. A., \& Walker, L. E. A. (Eds.). (1988). Feminist psychotherapies: Integration of therapeutic and feminist systems. Norwood, NJ: Ablex Publishing. 
Enns, C. Z. (1997). Feminist theories and feminist psychotherapies: Origins, themes, variations. Haworth innovations in feminist studies. New York: Harrington Park Press/The Haworth Press.

Enns, C. Z. (1993). Twenty years of feminist counseling and therapy: From naming implementing multifaceted practice._The Counseling Psychologist, 21, 3-87.

Eugster, S. L., \& Wampold, B. E. (1996). Systematic effects of participant role on evaluation of the psychotherapy session. Journal of Consulting and Clinical Psychology, 64 (5), 1020-1028.

Fausto-Sterling, A. (1997). Beyond difference: A biologist's perspective. Journal of Social Issues, 53(2), 233-258.

Friedan, B. (1963). The feminine mystique. New York: Dell.

Gerstmann, E. A., \& Kramer, D. A. (1997). Feminist identity development: Psychometric analyses of two feminist identity scales. Sex Roles, 36 (5-6), 327348.

Gilbert, L. A. (1980). Feminist therapy. In A. M. Brodsky \& R. T. Hare-Mustin (Eds.), Women and psychotherapy (pp. 245-266). New York: Guilford Press.

Gilbert, L. A. (1999). Reproducing gender in counseling and psychotherapy: Understanding the problem and changing the practice. _Applied \& Preventive Psychology, 8 (2), 119-127.

Gilbert, L. A., \& Osipow, S. H. (1991). Feminist contributions to counseling psychology. Psychology of Women Quarterly, 15 (4), 537-547.

Gilbert, L. A., \& Rader, J. (2001). Current perspectives on women's adult roles: Work, 
family, and life. In R. K. Unger (Ed.), Handbook of the psychology of women and gender (pp. 156-169). New York: John Wiley \& Sons.

Gilbert, L. A., \& Rader, J. (2001). Counseling and psychotherapy: Gender, race/ethnicity, and sexuality. In J Worell (Ed.), Encyclopedia of women and gender (Vol. I). San Diego, CA: Academic Press.

Gilbert, L. A., \& Rossman, K. M. (1993). The third decade of feminist therapy and the personal is still political. Counseling Psychologist, 21 (1), 97-102.

Gilbert, L. A., \& M. Scher (1999). Gender and sex in counseling and psychotherapy. Boston: Allyn and Bacon.

Greer, G. (1971). The female eunuch. New York: Bantam.

Hackett, G., Enns, C. Z., \& Zetzer, H. A. (1992). Reactions of women to nonsexist and feminist counseling: Effects of counselor orientation and mode of information delivery. Journal of Counseling Psychology, 39, 321-330.

Hare-Mustin, R. T. (1994). Discourses in the mirrored room: A postmodern analysis of therapy, Family Process, 33, 19-35.

Hare-Mustin, R. T., \& Marecek, J. (1990). Gender and the meaning of difference. In R. T. Hare-Mustin and J. Marecek (Eds.). Making a difference: Psychology and the construction of gender. New Haven: Yale University Press.

Hatcher, R. L. (1999). Therapists' views of treatment alliance and collaboration in therapy, Psychotherapy Research, 9 (4), 405-423.

Hatcher, R. L., \& Barends, A. W. (1996). Patients' view of the alliance in 
psychotherapy: Exploratory factor analysis of three alliance measures. Journal of Consulting \& Clinical Psychology, 64 (6), 1326-1336.

Henley, N. M., Meng, K., O'Brien, D., McCarthy, W. J., \& Sockloskie, R. J. (1998).

Developing a scale to measure the diversity of feminist attitudes. Psychology of Women Quarterly, 22, 317-348.

Heppner, P. P, Kivlighan, D. M., \& Wampold, B. E. (1992). Research design in counseling, Pacific Grove, CA: Brooks/Cole Publishing Company.

Hill, C. E., Nutt, E. A., \& Jackson, S. (1994). Trends in psychotherapy process research: Samples, measures, researchers, and classic publications. Journal of Counseling Psychology, 41 (3), 364-377.

Hill, C. E., Thompson, B.J., \& Williams, E. N. (1997). A guide to conducting consensual qualitative research. The Counseling Psychologist, 25 (4), 517-572.

Hill, M., \& Ballou, M. (1998). Making feminist therapy: A practice survey. Women \& Therapy, 21 (2), 1-16.

Horney, K. (1939). New ways in psychoanalysis. New York: Norton.

Horvath, A. O., \& Greenberg, L. S. (1989). Development and validation of the Working Alliance Inventory. Journal of Counseling Psychology, 36 (2), 223-233.

Hyde, J. S. (1994). Can meta-analysis make feminist transformations in psychology? Psychology of Women Quarterly, 18, 451-462.

Juntunen, C. L., Atkinson, D. R., Reyes, C., \& Gutierrez, M. (1994). Feminist identity and feminist therapy behaviors of women psychotherapists. Psychotherapy, 31 (2), 327-333. 
Kravetz, D., Marecek, J., \& Finn, S. (1983). Factors influencing women's participation in consciousness-raising. Psychology of Women Quarterly, 7, 257-271.

Krupnick, J. L., Sotsky, S. M., Simmens, S., Moyer, J., Elkin, I., Watkins, J., \&

Pilkonis, P. A. (1996). The role of the therapeutic alliance in psychotherapy and pharmacotherapy outcome: Findings in the National Institute of Mental Health Treatment of Depression Collaborative Research Program. Journal of Consulting \& Clinical Psychology, 64 (3), 532-539.

Lincoln, Y., \& Guba, E. (1985). Naturalistic inquiry. New York: Sage.

Marecek, J. (2001). Bringing feminist issues to therapy. In B. Slife, R. Williams, \& S. Barlow (Eds.), Critical issues in psychotherapy: Translating new ideas into practice. Thousand Oaks, CA: Sage.

Marecek, J. (2001). Disorderly constructs: Feminist frameworks for clinical psychology. In R. K. Unger (Ed.), Handbook of the psychology of women and gender (pp. 303316). New York: John Wiley \& Sons.

Marecek, J., \& Hare-Mustin, R. T. (1991). A short history of the future: Feminism and clinical psychology. Psychology of Women Quarterly, 15, 521-536.

Marecek, J., \& Kravetz, D. (1998). Power and agency in feminist therapy. In I. B. Seu, M. C. Heenan, et al. (Eds.), Feminism and psychotherapy: Reflections on contemporary theories and practices. Perspectives on psychotherapy. (pp. 13-29). Thousand Oaks, CA: Sage Publications.

Marecek, J., \& Kravetz, D. (1998). Putting politics into practice: Feminist therapy as feminist praxis. Women \& Therapy, 21 (2), 17-36. 
Marecek, J., Kravetz, D., \& Finn, S. (1979). Comparison of women who enter feminist therapy and women who enter traditional therapy. Journal of Consulting \& Clinical Psychology, 47 (4), 734-742.

McNamara, K., \& Rickard, K. M. (1989). Feminist identity development: Implications for feminist therapy with women. Journal of Counseling \& Development, 68 (2), 184-189.

Moradi, B., Fischer, A.R., Hill, M.S., Jome, L.M., \& Blum, S.A. (2000). Does "feminist" plus "therapist" equal "feminist therapist"?: An empirical investigation of the link between self-labeling and behaviors. Psychology of Women Quarterly, 24, 285296.

Orlinsky, D. E., \& Howard, K. I. (1986). The psychological interior of psychotherapy: Explorations with the Therapy Session Reports. In L. S. Greenberg and W. M. Pinsof (Eds.), The psychotherapeutic process: A research handbook (pp. 477501). New York: Guilford Press.

Perkins Gilman, C. (1973). The yellow wallpaper. New York: Feminist Press.

Rickard, K. M. (1989). The relationship of self-monitored dating behaviors to level of feminist identity on the Feminist Identity Scale. Sex Roles, 20 (3-4), 213-226.

Robinson, D., \& Worell, J. (1991). The Therapy with Women Scale (TWS). Unpublished manuscript, University of Kentucky, Lexington.

Rosewater, L. B., \& Walker, L. E. (Eds.), Handbook offeminist therapy: Women's issues in psychotherapy. New York: Springer Publishing.

Sadker, M., \& Sadker, D. (1994). Failing at fairness: How America's schools cheat girls. 
New York: Scribners.

Safran, J. D., \& Muran, J. C. (Eds.). (1998). The therapeutic alliance in brief psychotherapy. Washington, DC: American Psychological Association.

Samstag, L. W., Batchelder, S. T., Muran, J. C., Safran, J. D., \& Winston, A. (1998). Early identification of treatment failures in short-term psychotherapy: An assessment of therapeutic alliance and interpersonal behavior. Journal of Psychotherapy Practice \& Research, 7 (2), 126-143.

Task Force on Outcomes in Feminist Therapy (1999, August). Report to the executive committee of Division 35, The Psychology of Women. Presented at the annual meeting of the American Psychological Association, Boston.

Tichenor, V., \& Hill, C. E. (1989). A comparison of six measures of working alliance. Psychotherapy, 26 (2), 195-199.

Worell, J., Chandler, R., \& Robinson, D. (1996). Client Therapy with Women Scale. Unpublished manuscript, University of Kentucky, Lexington.

Worell, J., \& Johnson, N. G. (Eds.) (1997). Shaping the future of feminist psychology: Education, research, and practice. Washington, DC: American Psychological Association.

Worell, J., \& Johnson, D. (2001). Therapy with women: Feminist frameworks. In R. K. Unger (Ed.), Handbook of the psychology of women and gender (pp. 317-329). New York: John Wiley \& Sons.

Worell, J., \& Remer, P. (1992). Feminist perspectives in therapy: An empowerment model for women. Chichester, England: John Wiley \& Sons. 
Worell, J., \& Remer, P. (2003). Feminist perspectives in therapy: Empowering diverse women $\left(2^{\text {nd }}\right.$ Ed. $)$ New York: John Wiley \& Sons.

Worell, J., \& Robinson, D. (1993). Feminist counseling/therapy for the 21st century. Counseling Psychologist, 21 (1), 92-96.

Wyche, K. F., Rice, J. K., Cantor, D., Claster, B., Fodor, I., Gregory, C., Hassinger, J., Keita, G. P., Lerman, H., Rawlings, E., Rocchio, L., Rosewater, L. B., Silverstein, L., Walker, L., Brown, L. S., \& Brodsky, A. M. (1992). The future of feminist therapy. Psychotherapy, 29 (1), 51-57. 


\section{Vita}

Jill Elaine Rader was born in Beeville, Texas on January 27, 1967, the daughter of Doris and G.W. Dickinson. After completing her work at Pleasanton High School in Pleasanton, Texas in 1985, she attended Baylor University in Waco, Texas. She received her Bachelor of Arts degree in Journalism in 1989 and her Master of International Journalism degree in 1993. After this time, she worked as a newspaper reporter in Texas and New York. She then entered the Counseling Psychology doctoral program at the University of Texas at Austin in 1997. While a student in the Counseling Psychology program, she authored and co-authored articles and book chapters related to feminist therapy and gender issues in counseling. After finishing coursework, she completed her clinical internship at the University of Pennsylvania in July of 2003. She then joined Duquesne University's Psychology Department as an Assistant Professor in the Fall of 2003.

Permanent Address: 5742 Northumberland Street, Apt. 2, Pittsburgh, PA 15217

This dissertation was typed by the author. 